\title{
Impact of Renewable Energy on Carbon Dioxide Emission Reduction in Bangladesh
}

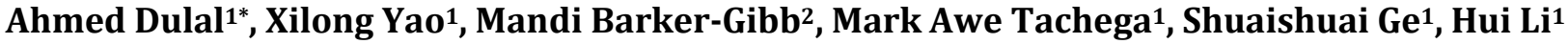 \\ ${ }^{1}$ College of Economics and Management, Taiyuan University of Technology, Taiyuan, China \\ ${ }^{2}$ School of Biological Science, Alumni, Monash University, Clayton Victoria, Australia \\ Email: *dulalahmed.p@gmail.com, dulalahmed2017@link.tyut.edu.cn
}

How to cite this paper: Dulal, A., Yao, X.L., Barker-Gibb, M., Tachega, M.A., Ge, S.S. and Li, H. (2021) Impact of Renewable Energy on Carbon Dioxide Emission Reduction in Bangladesh. Journal of Power and Energy Engineering, 9, 134-165. https://doi.org/10.4236/jpee.2021.95009

Received: April 19, 2021

Accepted: May 28, 2021

Published: May 31, 2021

Copyright ( 2021 by author(s) and Scientific Research Publishing Inc. This work is licensed under the Creative Commons Attribution International License (CC BY 4.0).

http://creativecommons.org/licenses/by/4.0/

\begin{abstract}
Economic growth and industrialization often default to a great dependency on fossil fuels (FF) to supply power needs. The carbon rich nature of $\mathrm{FF}$ combustion can impact global warming. Therefore, it is conducive to transition from FF to renewable energy (RE). The present study aimed to address if replacement of a single FF by RE can mitigate carbon emissions. We conduct the study in a country undergoing mass urbanization and challenging energy demands. Data from energy resources in the Power \& Energy Sector Master Plan (PSMP2016; Bangladesh) are analyzed over the 2017-2021 trajectory. Two scenarios for imports, oil and coal are assessed. Environmental input output (E-IO) analysis and percentage equivalence analysis measured data variables. The data is then further disaggregated into an emission reduction (ER) model with sensitivity analysis to measure carbon emission reduction when each FF source is substituted by RE. Results show the percentage share of energy generation capacity by both coal and RE increase over time. Solar and wind power contribute to the increase in RE. When oil is imported a $1 \%$ increase in oil, coal, and gas-based energy generation capacity increases carbon emissions by $1.25 \%, 1.48 \%$ and $0.93 \%$, respectively. $1 \%$ increase in RE produces negligible carbon emissions $(0.0042 \%)$. There was little difference in the percentages of carbon emissions when coal is imported. Substituting any FF with RE of equal energy capacity does not, in the short term, reduce carbon emissions in either scenario. Therefore, we conclude that for long term clean energy prospects in Bangladesh, RE needs to be developed to operate at greater capacity in conjunction with other carbon management factors. The research findings herein offer insights for clean energy implementation in developing nations.
\end{abstract}

\section{Keywords}

Carbon Emission, Carbon Emission Reduction, Renewable Energy, Fossil Fuels, Environmental Input Output (E-IO) 


\section{Introduction}

In 2019 , the global temperature increased by $1.15^{\circ} \mathrm{C}$ compared to the pre-industrial average, registering $0.95^{\circ} \mathrm{C}$ above the twentieth century average [1]. Increased carbon emission is documented as the major factor contributing to this temperature rise, mostly due to the combustion of fossilized fuel (FF) for manufacturing and energy needs. As such, the relationship between carbon emissions and source attributes has dominated environmental research fields [2] [3] [4] and scholars have worked to determine the effects of those interconnections on environmental degradation [4] [5]. Population growth and economic development enhance energy consumption and industrialization often defaults to a great dependency on FF's to supply power needs. This paradigm is environmentally costly in terms of carbon release and has led to greater interest in renewable energy (RE) technologies [6]. Nevertheless, carbon emission reduction paradigms are complex, particularly in such in developing countries. Such countries often undergo rapid urbanization and industrialization and face several dilemmas. One is of maintaining and improving energy capacity to fulfill energy demands for economic growth and reduce poverty. Second, energy demands in these countries can increase rapidly both in terms of explosive population growth and regional urbanization [7] [8]. Third, although the transition from FF to $\mathrm{RE}$ is one of the best options for mitigating carbon emissions, there are barriers to this process in poorer countries. These usually center on the short terms cost of RE, and relative amount of energy generation for supply and demand [2] [9].

How does a developing country keep up with energy demands and while at the same time mitigate carbon emissions? It is a perplexing question. The current study focuses on evaluating carbon emissions derived from different energy sources within a society that is undergoing rapid and challenging issues in industrial development. It aims to investigate if advances in RE contribute to CE reduction, and how it could best be implemented in a mixed energy system. We chose to study Bangladesh, as this country is undergoing mass urbanization, increases in population density, and insufficient power generation. The analysis of such a model can then act as benchmark tool when considering RE technologies in other developing nations. The remainder of section provides a general background on energy production and carbon emission output in Bangladesh. Next, we include some common methods to analyze carbon emission reduction, and the models adopted by this paper. Section 2 provides literature review, Section 3 provides the methodology, Section 4 provides the results and the discussion, and concluding remarks are given in Section 5.

\section{Literature Review}

\subsection{Energy Generation Expansion Plan in Bangladesh}

Bangladesh has one of the highest rates of pollution in the world and is experiencing dramatic environmental degradation in the face of explosive population 
growth. Urban population rose from less than 40 million in 2006 to more than 55 million by 2015 [10]. The present low cost of electricity plays a large role in the economic growth and development of Bangladesh. At the country's independence from Pakistan in 1971 only $3 \%$ of the population had access to the electricity and by 2009, 2012 and 2017 this figure increased to $47 \%, 59.6 \%$ and $80 \%$ respectively [11]. However, there is a continuous struggle to overcome energy crisis. Population growth, system losses, and the country's prior dependence on a now dwindling supply of natural gas are major factors in the struggle. In 2017 the grid capacity was 15,821 MW, including 16,070 MW imported and 2200 MW captive power capacity [11] [12], and 16,070 MW including off-grid RE [13]. By June 2018, the installed generation capacity including captive power, was approximately 18,753 MW. Although this shows a considerable increase in installed capacity in a small range of years, there is still increasing demand for electricity. The government has committed itself at looking for solutions from all angles including importing fuel sources, installing new power plants, and buying electricity from independent power producers to meet the demands. An intergovernmental agreement has been signed between Bangladesh and Russia to install a 2-generation nuclear power plant at Rooppur and Pabna (60 years lifetime). There will be 2 units of $1200 \mathrm{MW}$ each nuclear plant. Rooppur is expected to be commissioned 2024 [14]. This future electricity source gives hope to the government that electricity cost will be competitive though initial investment is very high. Bangladesh is also attracting private investment and independent power producers, and these are producing $54 \%$ of the total installed electricity [12] [15] [16]. In recent years, there have also been improvements in technical and distribution losses which decreased from $16.9 \%$ in 2009 to $12.2 \%$ in 2017 [12].

Due to shortages in natural gas, Bangladesh is increasingly switching to oil and coal-based power generation [17]. Oil and coal are highlighted as the first track, short term option to meet the rising electricity demand in this country [12]. These fuel sources are preferable as they can generate a significant amount of power within the shortest time. However, oil-based power plants are costly compared to gas-based plants, and oil contributes to extensive environmental pollution. These factors impede the process of oil being a long-term solution to alleviate the shortage of natural gas in Bangladesh. The use of indigenous coal is also being encouraged. The plan is to reach 23,692 MW generation from coal by 2022 [18]. Coal, however, is also environmentally costly in terms of mining and pollution [16]. In fact, Bangladesh is predicted to be one of the most carbon emitting countries by 2025 financial year with $83 * 10^{6}$ tons of $\mathrm{CO}_{2}$ from 132,520 GWh electricity generation [19].

The PSMP-2016 of Bangladesh [20] is a resource that lists all available energy producing projects in the country and is updated approximately every $5-6$ years. It documents that $10 \%$ of the nation's grid should be achieved from RE by 2020 and $20 \%$ by 2030 . These targets are set according to the availability of RE sources in the country. Nevertheless, all of these RE sources together fail to meet 
proposed grid demands for electricity. RE projects need to be at least developed in accordance as planned to account for a total of 2651MW of electricity generation by the year 2022 [12]. If so, ongoing and forecasted projects RE could feed the national energy grid at a share of around $10 \%$ by 2022 [12] [21]. Due to heightened energy demand, the reality for Bangladesh's power grid in the short term is a mixed energy system consisting of both FF and RE projects.

Research and development are paving the way toward decreasing the cost of $\mathrm{RE}$, although more research needs to be conducted on not just installing different kinds or renewable energy, but increasing the energy capacity of RE and other sustainable technologies. Furthermore, there needs to be more direction on how best to implement RE practices for energy generation capacity and carbon emission reduction in a mixed energy system.

\subsection{Methods for Studying Carbon Emission Reduction}

Several methods have been used to investigate the carbon emission in different sectors and regions. Utilizing the zero-sum gains data envelopment analysis (ZSG-DEA) model, Wu et al. [22] examined the carbon reduction potential of China's key industries and found the electric power, iron and steel industries have the greatest potential for emissions reduction. Lin and Ahmed [23] applied a Logarithmic Mean Divisia Index (LMDI) method to model a variety of factors with carbon emission reduction potential in Pakistan and found population and GDP contributed to increased carbon emissions. The effect of FF was mixed. The LMDI model and input output structural decomposition analysis has also used to investigate the long-term relationship among carbon emissions and the main factors affecting energy intensive industries in China. These authors illustrated that industrial scale and labor production are the main contributors to carbon emission whereas energy intensity has a negative contribution [24]. Yu et al. [25], constructed a panel quantile model to examine how the development of renewable energy and a decline in energy intensity relate to carbon emission reductions in China. Recently, Li et al. [3], used a dynamic Computable General Equilibrium (CGE) model to investigate how the energy supply-side and demand-side policies for energy saving and carbon emission reduction could be synergistic. Xuan et al. [26] used the difference-in-difference (DID) model to promote the reduction of carbon emissions in China's trading policies. The results show that carbon emission trading policies, economic development, technological research level and opening to the outside world can significantly reduce carbon dioxide emission intensity and promote carbon emission reduction. Using a constrained performance index measure (CPIM) model Ding et al. [27] analyze the strong relationship between energy saving performance and carbon ER in China. Using a panel quantile regression model method, Khan et al. [9] show that financial development has increasing influence on RE consumption. These studies have used many different variables like foreign direct investment, GDP, economic growth, urbanization, and democracy to account for population use of resources [27] [28]. Not only are there discrepancies between the methods 
and outcome many of these studies are in more developed countries. Quantifying environmental pollution using per-head indicators can also be somewhat insufficient when comparing economically developed countries with underdeveloped countries. This is due to large differences in social life, socio-economic status, large gaps in energy-demand and industry in poorer countries [4]. Research objectives would be improved if energy generating activities were assessed individually, by source, instead of per head.

Indirect effects of energy direction also exist, alongside direct effects. These have important consequences on the environment. Some findings confirm carbon emissions have a direct effect on energy production output [9]. In addition, for energy sources to reach their electricity form, they are required to pass through processes that result in different power capacities and release different amounts of carbon per unit of power generated. Furthermore, different fuel sources can emit different quantities of carbon per unit of power generated. For example, CEI intensity from coal-based power generation is nearly twice the CEI of gas-based power generation [19]. RE engages with negligible direct carbon emissions than fossil fuels. In recent years, much attention has been given to extended input-output models (E-IO) to account for energy use and environmental pollution. Notable works conducted by Cumberland 1966 [29], Leontief and Ford 1972 [30], Bullard-Herendeen 1975 [31], and Griffin and Gregory 1976 [32], have written extensively about the model. E-IO models can provide an appropriate framework for analyzing carbon emission by accounting for each activity that happens in the energy cycle. This method can account for the indirect influence of carbon emissions on RE as well as direct effects. For instance, Peng et al. [33], employed the E-IO model to investigate the potential pathways toward energy-related carbon emission reduction in heavy industrial regions of China. They investigate the potential ways for these zones to achieve energy-related carbon emission reductions, with three northeastern provinces accounting for about $1 / 10$ of China's energy consumption and $1 / 6$ of China's $\mathrm{CO}_{2}$ emissions. Jiang et al. [34], use input-output analysis to focus on structural carbon emission during energy supply and energy demand in Chinese industries and find that in the Chinese energy system, the carbon emissions of traditional high-carbon energy sources (such as raw coal, diesel, and fuel oil) slowly decline, whereas use of low-carbon clean energy sources (such as natural gas) increase. Ren et al. [35] consider an Epsilon-Based Measure (EBM) Data envelopment analysis model from an input-output perspective in the solar photovoltaic industry to analyze carbon emission reduction and efficiency. Luo et al. [36] use the E-IO model to compare and analyze the specific driving forces of change in carbon emissions based on the disaggregation of China's power industry. They illustrate that the embodied carbon emissions of each clean energy sector are relatively lower than the carbon emissions produced by thermal power generation. Recently, Chard et al. [37] use the input-output analysis of environmental expansion to quantify the carbon footprint of selected Australian equity investments. The analysis also calculates the representative employment footprint of 
these investments to observe the broader impact of the transition to a low-carbon economy.

The present study wishes to address if replacement of a single FF by RE can mitigate carbon emissions. It is still unclear as to where and how in the energy nexus RE should be prioritized, especially in developing countries. Therefore, the current study quantifies energy production and direct carbon emission output of FF and RE resources in Bangladesh and engages an ER model. The study utilizes the 5-year trajectory proposed in the PSMP-2016 which is close to a new review. The ER model is useful as it considers both baseline and projected scenarios and can comprehensively capture the details of both scenarios and compute the emission reduction for the investigated sources [38]. We not only assess the impact of listed energy sources from the PMSP-2016, by using the ER model with sensitivity analysis, we can analyze the degree of carbon emission reduction when any FF is replaced by RE technology built to equal energy generation capacity. This model can then assess where, in the mixed energy nexus, CE reduction can be best implemented.

On this premise, this study employs 3 main steps; 1 ) we quantify the relationship between energy generation capacity from each source and the relative carbon emission with the support of E-IO analysis; 2) we examine RE effects on carbon reduction by adopting an ER model; and finally, 3) the baseline carbon emission and ER results are subjected to sensitivity analysis. Using this modeling system, we can assess each FF one at a time, against RE, to find which type of FF is best replaced by RE to enhance carbon emission reduction in a mixed energy system. By adopting this approach, we yield useful insight into relationships that exist in the carbon-energy nexus in Bangladesh.

\section{Methods and Models}

This paper investigates the relationship between RE, FF and carbon emissions in Bangladesh, and utilizes data from the Peoples Republic of Bangladesh Power \& Energy Sector Master Plan (PSMP-2016) [20]. This plan projects power generation as assessed from many governmental and private organizations in the Bangladeshi energy sector. This is compiled by reporting time, location and which of the energy sources will be adopted for proposed power projects and usually gets updated every 5 - 6 years. The current study aims to investigate how energy generation capacity and carbon output manifests in term of a short-term trajectory. Data are used up to the next estimated revision in 2021, thus uses data projected from the PSMP-2016 over 2017-2021 [12] [39] [40] [41]. The variables are energy capacity expressed in MW from each of the available energy sources, carbon emission intensity (CEI) in $\mathrm{tCO}_{2} / \mathrm{MWh}$, and time. Energy capacity is used as an independent variable for the environmental input-output analysis and calculated in Excel Scenario. Energy generation (MWh), carbon emissions $\left(\mathrm{tCO}_{2)}\right.$ and carbon emission reduction are dependent variables which are calculated inside the models. The E-IO results express the quantity of carbon emissions from each type of energy resource. The E-IO results are then disaggregated into base- 
line emission (BE) and proposed emission (PE) to build the emission reduction (ER) model. Indigenous gas is heavily used in Bangladesh. These reserves will soon be exhausted. There are plans to import LPG gas for cleaner energy [42]. The current PSMP, however, does not provide whether imported sources are coal or oil. In addition, there is little relevant information in the literature on the amount of these imports to Bangladesh for the PSMP-2016. Therefore, we quantitated data of all energy generation capacity output and respective carbon emission output in 2 scenarios. In Scenario one, oil is used as the imported FF and in Scenario two, coal is used as the imported FF. We quantify the energy generation capacity and respective carbon emission output within the relevant scenario. Indigenous coal, oil, and gas, from the PSMP-2016 are also calculated in each scenario. In some instances, data for total oil or coal is shown. This is the sum of the indigenous and imported sources and is mainly used for diagrammatical purposes. The data for gas is from indigenous sources so remains the same for both scenarios, as does RE.

\subsection{Data Analysis}

\subsubsection{Identification of Carbon Emission Sources and Determination of CEI}

To determine the CEI of indigenous FF in Bangladesh, the study repeats procedures by Ashish et al. [24]. Due to the case study similarity and considerable on-site survey taken in their study, the current study used the carbon emission factor $\left(\mathrm{KgCO}_{2} / \mathrm{kg}\right)$ and heat value $(\mathrm{KWh} / \mathrm{kg})$ for biomass predicted by Baul et al. [43]. CEI of the FF is calculated by using data from indigenous FF power stations input into Hybrid Optimization of Multiple Energy Resources (HOMER) software [19].

$$
\mathrm{CEI}=\mathrm{Hv} / \mathrm{CEF}
$$

CEI: carbon emission intensity of energy source $\left(\mathrm{tCO}_{2} / \mathrm{MWh}\right)$.

$\mathrm{Hv}$ : heat value of fuel used (MWh/ton).

CEF: carbon emission factor of the fuel used $\left(\mathrm{tCO}_{2} / \mathrm{ton}\right)$.

\subsubsection{Environmental Input-Output Analysis (E-IO)}

The current E-IO analysis quantifies the effect that each type of FF and RE energy source makes in a mixed energy system. To build an E-IO that illustrates the relationship between FF, RE and carbon emissions, it is necessary to recall the movements that happen in that cycle. The existence of carbon emission output usually requires an energy process to increase, and as the energy process grows, carbon emission expands. Released carbon emission output thus depends on energy generation activity. The E-IO method accounts for the carbon emission output from energy activity and describes the indirect influence of carbon emission output in the cycle. To generate the output of carbon emission activity and the final requirements in energy generation activity, the model records the input required for each countable activity:

1) a) RE effects on RE; b) RE effects on FF; c) RE effects on CE. 
2) a) FF effects on FF; b) FF effects on RE; c) FF effects on CE.

3) a) CE effect on CE; b) CE effects on RE, c) CE effect on FF.

\subsubsection{Mathematical Model}

In many cases, energy sources are extracted and treated in power plants, Afterwards, the whole process provides electrical energy ( $\mathrm{MWh}$ ) accompanied with relevant amount of carbon emission output depending on the energy sources exploited. Generally, carbon emissions calculations depend on activities from which carbon is emitted and its emission intensity Equations (2) and (3) illustrate energy generation as the basic activity in the study.

$$
\begin{gathered}
E=\sum \mathrm{CEI}_{i} * \mathrm{Act}_{i} \\
E_{G}=\frac{\sum_{i} \mathrm{Fu} * \mathrm{NCV} * n_{e}}{3.6}
\end{gathered}
$$

\section{E: Total Emission}

CEI: Carbon emission intensity

Act: Activity (Energy generation)

$E_{G}$ : Energy generated (MWh)

Fu: Fuel used

NCV: Net calorific value

$\eta_{e}$ : Energy capacity factor

The CEI, which accounts, for the connection between energy and carbon emission, depends on power generation and the energy source type (Equation (4)). Therefore, the CEI represents the amount of CE released to the atmosphere per unit of generated energy.

$$
\begin{gathered}
E=\frac{\sum_{i} \mathrm{Fu} * \mathrm{NCV} * \mathrm{CEI}}{E_{G}} \\
E=\frac{3.6 * \mathrm{CEI}}{n_{e}}
\end{gathered}
$$

This study accounts for both grid and off-grid power plants. Therefore, $E_{G}$ is calculated based on the projected power plant energy capacity factor $\left(L_{f}\right)$ in addition to its time span. $L_{f}$ is assumed to be $50 \%$ for all energy generation types adopted in this study. $P$ is productivity. $L_{f}$ and the time span are factored on the power captured by the power plant to yield the energy generated for electricity use.

$$
\begin{gathered}
E_{G}=P * L_{f} * 24 * 365 \\
E_{G}=P * 0.5 * 8760
\end{gathered}
$$

To calculate carbon emissions, the Equations (6) and (7) are combined to illustrate input and output variables. With Equations (8) E-IO analysis accounts for interconnection between energy generation and CE activities, and is used in Sections 4.3 and 4.4

$$
E=\sum(P * 0.5 * 8760)_{i} * \mathrm{CEI}_{i}
$$




\subsubsection{Emission Reduction Model (ER)}

The theory behind the term ER is to replace energy sources that emit high levels of carbon by active energy sources that release a lower or negligible quantity of carbon output. This paper uses the ER model to analyse any dependency of renewable energy progress on emission reduction. Of the RE sources listed in the PSMP-2016, the MWh of coal, oil, and gas and RE are integrated with their CEI. Each of the FF MWh and carbon emissions over a year are established to obtain $\mathrm{BE}$ values. The carbon emissions produced from $\mathrm{RE}$ are summed to make the project emission, which is subtracted from the BE to yield ER. The ER represents the ER by RE, when generating the same energy as each FF.

$$
\begin{gathered}
E_{R} * \mathrm{CEI}_{i}=\mathrm{BE}_{i} \\
\sum \mathrm{CE}_{\mathrm{R} i}=\mathrm{PE} \\
\mathrm{BE}-\mathrm{PE}=\mathrm{ER}
\end{gathered}
$$

ER: Total renewable energy capacity

$\mathrm{CEI}_{i}:$ carbon emission intensity of energy source $i$

$\mathrm{BE}_{i}$ : Baseline emission from energy source $i$

$\mathrm{CE}_{\mathrm{R}}$ : Carbon emission from RE source $i$

PE: Projected emission

ER: Emission reduction.

\subsubsection{Sensitivity Analysis}

Sensitivity analysis is carried out on baseline emissions, and is used to assess baseline carbon emissions and carbon emission reduction by RE when RE is modelled equal energy capacity as a FF. We model RE replacement for each of the fossil fuels for both scenarios. The analysis utilizes the "one-factor-at a-time" (OFAT) approach in Microsoft Excel, with ER results from the baseline year 2017 and the projected year 2021 input into the model. Sensitivity is analyzed at \pm 25 . These are chosen as the base parameters (nominal set) based on OFAT sensitivity method that operates under the practice of picking random sensitivity values for the analysis.

\section{Results}

For the following results, the CEI values for FF and RE are $0.90 \mathrm{KWh}, 0.76 \mathrm{KWh}$, $0.57 \mathrm{KWh}$ and $0.28 \mathrm{KWh}$ for coal, oil, gas, and biomass, respectively.

\subsection{Scenario 1: Energy Generation Capacity and Carbon Emission Output Using Imports as Oil}

Table 1 presents the direct effects on energy generation capacity activity from each type of energy source and their respective carbon emissions in Bangladesh over 2017-2021. Within-year total energy generation capacity and carbon emission out are shown in the bottom row, and the total energy generation capacity and carbon emission output over the total five year-period for each energy source and their percentage share are shown in the last 4 rows. 
Table 1. Energy generation capacity output (MW) and carbon emission from each FF source and RE energy sources per year and over the 5-year trajectory. Table illustrates scenario 1 which accounts for oil imports.

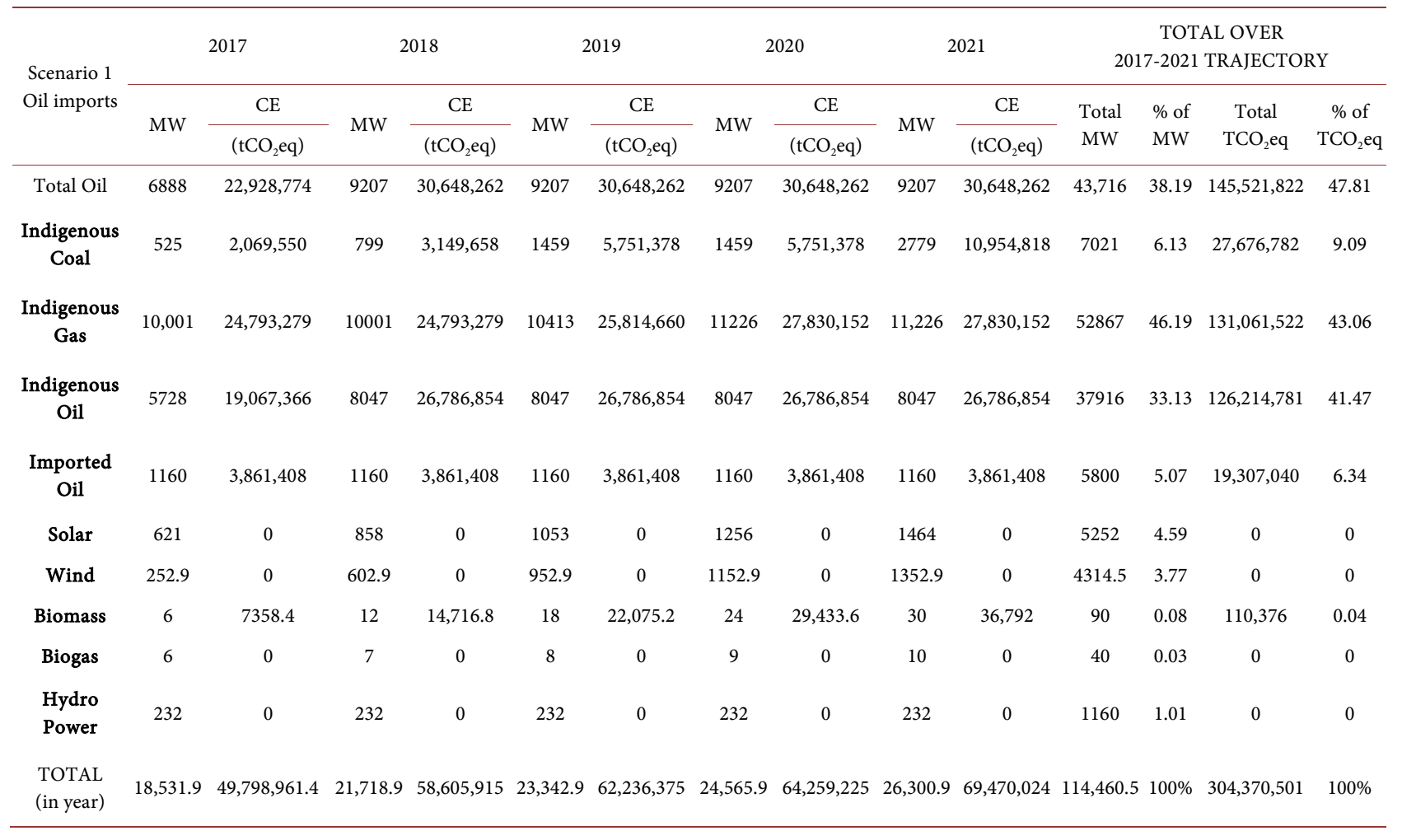

Total energy generation capacity increases in Bangladesh by 95,928.1 MW from the baseline year 2017 to the projected year, 2021. This energy generation capacity is influenced to different extents by each FF and RE. Total coal and gas energy generation capacity is $7021 \mathrm{MW}$ and $52,587 \mathrm{MW}$, respectively. Indigenous oil accounts for 37,916 MW of total energy generation capacity, while imported oil accounts for 5800 MW. In Scenario 1, total carbon emission output from FF energy generation capacity over the $2017-2021$ period is $27,676,782$ $\mathrm{tCO}_{2}$ eq from coal and $131,061,522.3 \mathrm{tCO}_{2}$ eq from gas. Carbon emission output from total oil sources is $145,521,822 \mathrm{tCO}_{2}$ eq. Of the oil sources, $126,214,780.8$ $\mathrm{tCO}_{2}$ eq is from indigenous oil, and 19,307,040 $\mathrm{tCO}_{2}$ eq from imported oil.

\subsubsection{Percentage Share of Total Energy Generation Capacity and Carbon Emission Output over 5 Years}

In this section of Scenario 1, we quantitated each FF and the combined RE energy sources as percentage share of total energy generation capacity over the 5 -year trajectory, as well as the percentage share of total carbon emission output. The results are represented in Figure 1.

Indigenous gas makes up one of the greatest shares of total carbon emission output (46.19\%) and this is sourced from $43.06 \%$ of gas's share of total energy generation capacity. Indigenous coal comprises one of the lower shares of total carbon output at $9.09 \%$ derived from $6.13 \%$ of the share of total energy generation capacity. Imported oil has the lowest share of total carbon emission output 


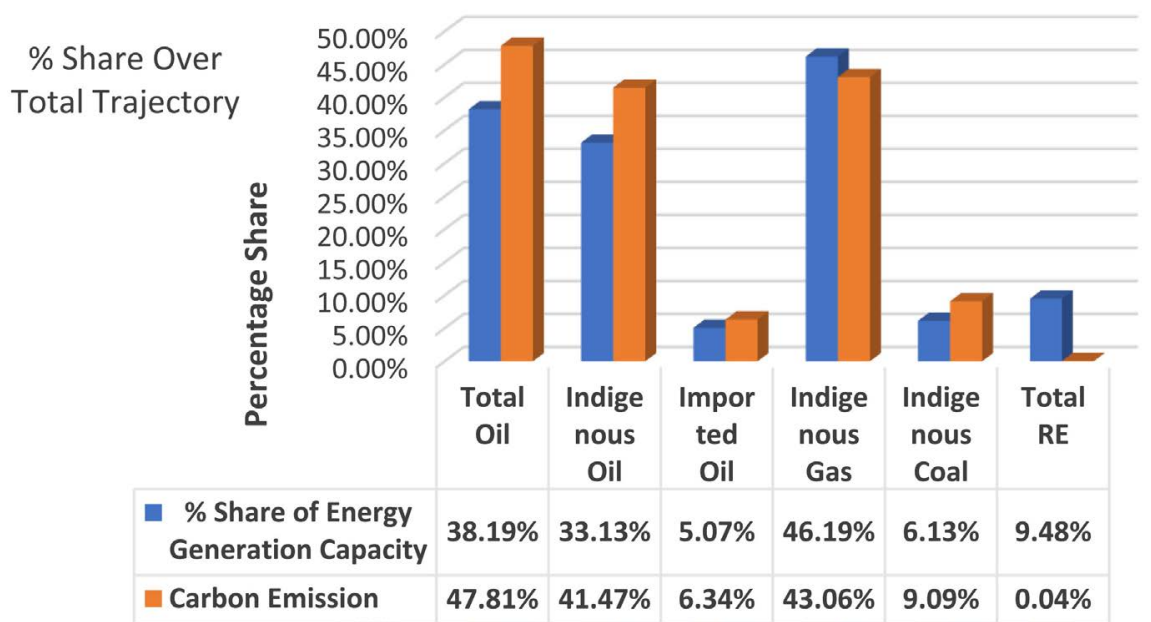

Figure 1. Scenario one: Oil. Percentage share of total energy generation capacity (MW) and relative carbon emissions by each fossil fuel (FF) source and all renewable energy (RE) resources combined over the 2017-2021 trajectory.

(6.34\%) and this is sourced from $5.07 \%$ of total energy generation capacity. On the other hand, total oil sources combined comprise the greatest share of total carbon emission output (47.81\%) from $38.19 \%$ of the share of total energy generation capacity. This is primarily sourced from indigenous oil which makes up $41.47 \%$ of the share of total carbon emission output from $41.47 \%$ of the total share of energy generation capacity. Therefore, indigenous oil appears to generate a high percentage of carbon output relative to its percentage share of total energy generation capacity. We examine this further in section 4.2.

It is surprising to find that the combined RE sources have a higher percentage share of total energy capacity than indigenous coal, with negligible carbon output. It is then of interest to quantitate energy generation capacity and total carbon output from each RE resource on an individual basis. They are also represented as a percentage share of total energy capacity and total $\mathrm{tCO}_{2}$ eq. These variables are presented graphically in Figure 2.

Solar and wind power primarily contribute to the increase in total RE energy generation capacity over the 5-year trajectory, providing $4.59 \%$ and $3.77 \%$ of the percentage share of total energy generation capacity, respectively. It can also be seen that each RE energy source has negligible carbon emission output; the exception being biomass at $0.04 \%$ of the share of total carbon output (Table 1 , Figure 2) for only $0.08 \%$ of the percentage share of total energy generation capacity. This is one illustration that biomass is a relatively inefficient fuel source in terms of energy generation capacity and potentially, for carbon emission reduction.

\subsubsection{Scenario 1: Energy Generation Capacity and Relative Carbon Output by Year}

Next, we look at the percentage share of energy generation capacity and relative carbon emission output within each individual year of the trajectory. Special 


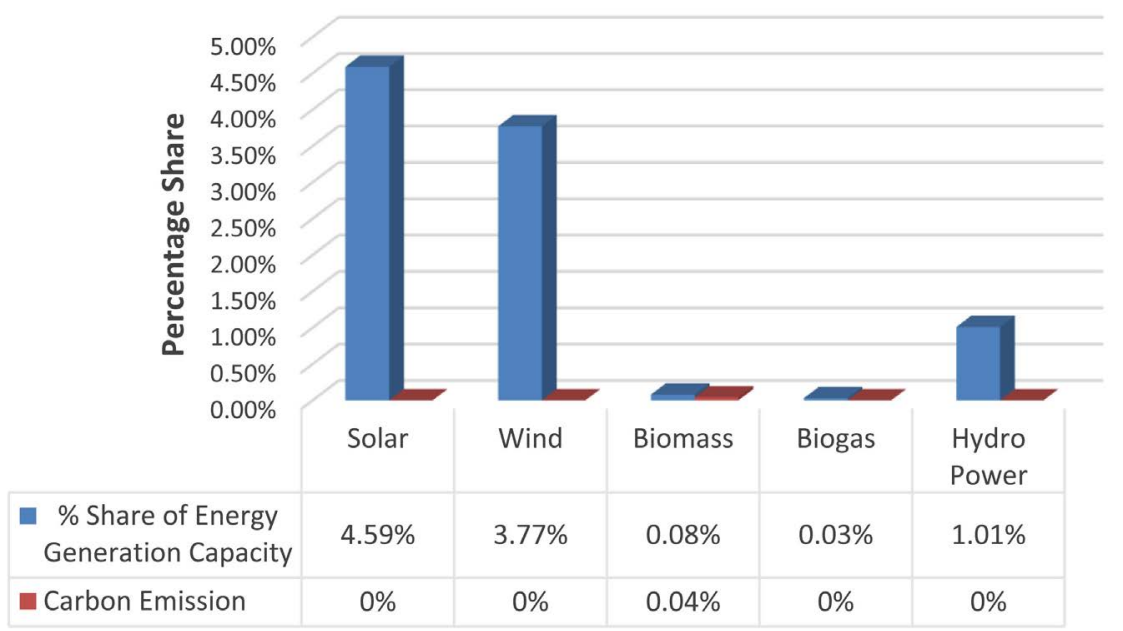

Figure 2. Percentage share of total energy generation capacity (MW) and relative carbon emissions by each renewable energy (RE) resource over the entire 2017-2021 trajectory. Data is calculated from total energy generation capacity and carbon emission from Scenario 1 , which accounts for imports as oil.

attention is placed on comparing the beginning of the trajectory (2017) and the projected year (2021) of the trajectory (Figure 3).

Quantitative data for other years are provided in the text. In this scenario, indigenous coal provides an extra 2254MW in 2021 compared to 2017 and provides an extra 8,885,268 $\mathrm{tCO}_{2}$ eq in 2021 compared with 2017. There is an extra $1225 \mathrm{MW}$ from gas in 2021 compared to 2017 and the projected increase in gas is $3,036,873 \mathrm{tCO}_{2}$ eq. Of the oil sources, indigenous oil provides the greatest percentage share of energy generation capacity and carbon emission output. The values amount to $7,719,488 \mathrm{tCO}_{2} \mathrm{eq}$ in the projected year, $2021 \mathrm{vs}$ the first year of the study, 2017.

To examine this further we analyzed the data from each source as a percentage share of total energy generation capacity and carbon emission output within each year. The percentage share of energy generation capacity of all oil sources only shows small fluctuations over each year of the study trajectory $(37.17 \%$ in $2017,42.39 \%$ in $2018,39.44 \%$ in $2019,37.48 \%$ in 2020 , and $35.01 \%$ in 2021 ). This is probably due to other sources changing in the energy mix. Carbon emission output by oil-based fuel contributes $46.04 \%$ of the percentage share in 2017 , $52.30 \%$ in $2018,49.24 \%$ in $2019,47.69 \%$ in 2020 and $44.12 \%$ in 2021.

Indigenous coal contributes to $2.83 \%$ of energy generation capacity in 2017 . However, the percentage energy generation capacity by coal rises steadily over time (2.83\% in $2017,3.68 \%$ in 2018 , to $6.25 \%$ in $2019,5.94 \%$ in 2020 ), increasing more than 3 -fold to $10.57 \%$ in 2021 . Carbon emissions by coal provide $4.16 \%$ of the share of carbon emission output in 2017. This rises to $5.37 \%$ in 2018, then to $9.24 \%$ and $8.95 \%$ in 2019 , and 2020 , respectively, and could be attributed to the increase in the share of energy generation capacity by coal over time. By 2021 there is almost a four-fold increase (15.77\%) in the percentage share of carbon emissions by coal. 


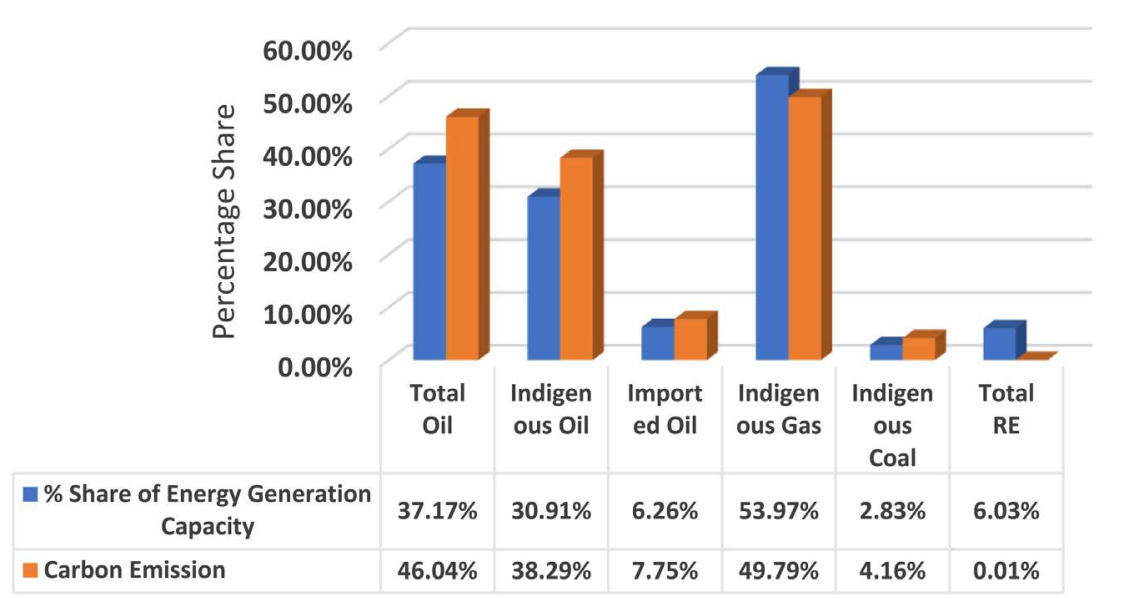

(a)

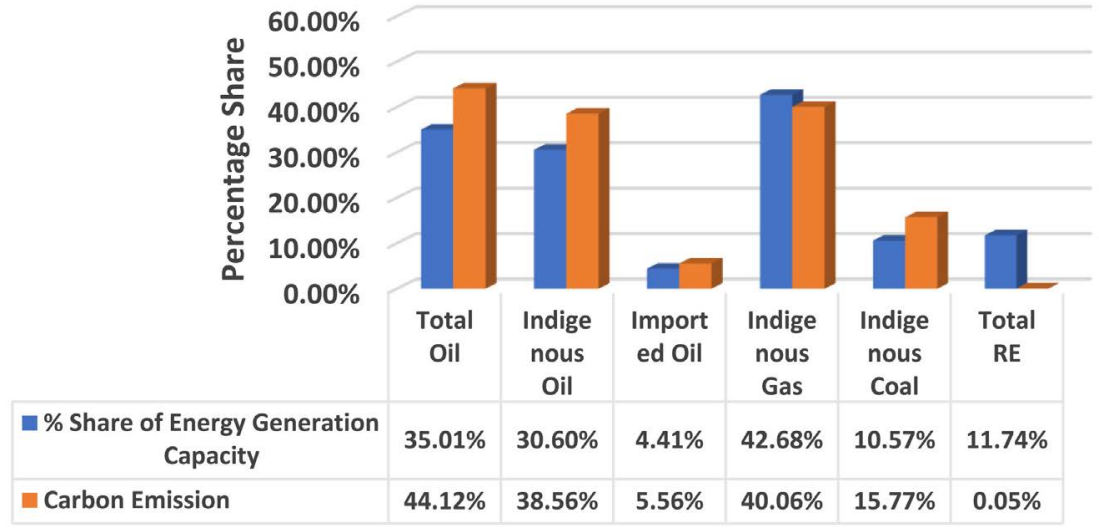

(b)

Figure 3. Scenario 1: Percentage share of energy generation capacity (MW) of each fossil fuel (FF), total combined renewable energy (RE) sources, and relative carbon emissions by each energy source in 2017 (Panel (a)) and 2021 (Panel (b)).

Gas shows the greatest percentage share of energy generation capacity (53.97\%) within the baseline year (2017). However, the percentage share of energy generation capacity by gas decreases over time (46.05\% in 2017, $46.05 \%$ in $2018,44.61 \%$ in $2019,45.70 \%$ in 2020 and $42.68 \%$ in 2021). By 2021, at the end of the trajectory, the percentage share of gas has dropped more than $10 \%$ to 42.68\% (Figure 3(a) compared with Figure 3(b)). Carbon emission output by gas in the trajectory closely follows its energy capacity output, also declining over time. The percentage share of carbon emission output by gas is $49.79 \%$ for $2017,42.31 \%$ in $2018,41.48 \%$ in $2019,43.31 \%$ in 2020 and $40.06 \%$ in 2021 , respectively.

The percentage chare of energy generation capacity by the combined RE sources increases substantially over the 5-year trajectory and is nearly 2-fold higher in 2021 than 2017 (Table 1, Figure 3). RE sources combined contribute $6.03 \%$ of the share of energy generation capacity in $2017,7.88 \%$ in $2018,9.7 \%$ in $2019,10.88 \%$ in 2020 , and $11.74 \%$ in 2021 . Carbon emissions by RE are negligible and are sourced from biomass $(0.01 \%$ in $2017,0.03 \%$ in $2018,0.04 \%$ in 2019 , 
$0.05 \%$ in 2020 and $0.05 \%$ in 2021). However, relative to other FF, biomass provides negligible carbon output.

Therefore, to summarize, gas has the highest share of energy generation capacity in both the baseline year and projected year, then indigenous oil. However, the percentage share of energy generation and carbon emissions gas declines considerably by 2021. Oil sources, specifically indigenous oil, have the greater percentage share of carbon emission output in both baseline and projected years, than gas. There is no change in the percentage share of energy generation capacity or carbon emission output from imported oil between 2017 and 2021. There is substantial growth in energy generation capacity by both coal and RE in the projected year 2021 vs the baseline line year. Coal but not RE, shows considerable growth in the percentage share of carbon emission output by 2021.

We then quantitated changes in energy generation capacity and carbon emissions of the individual RE sources between the baseline year of the trajectory (2017) and the projected year (2021) in this trajectory. These variables are illustrated as a percentage share of total within year energy generation capacity and carbon emission output in Table 2 and Figure 4.

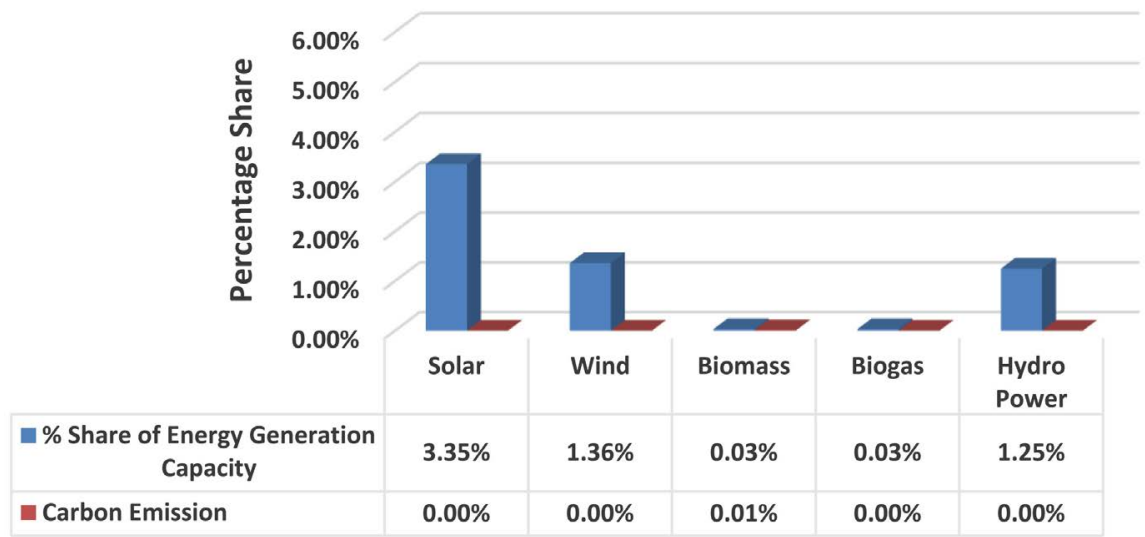

(a)

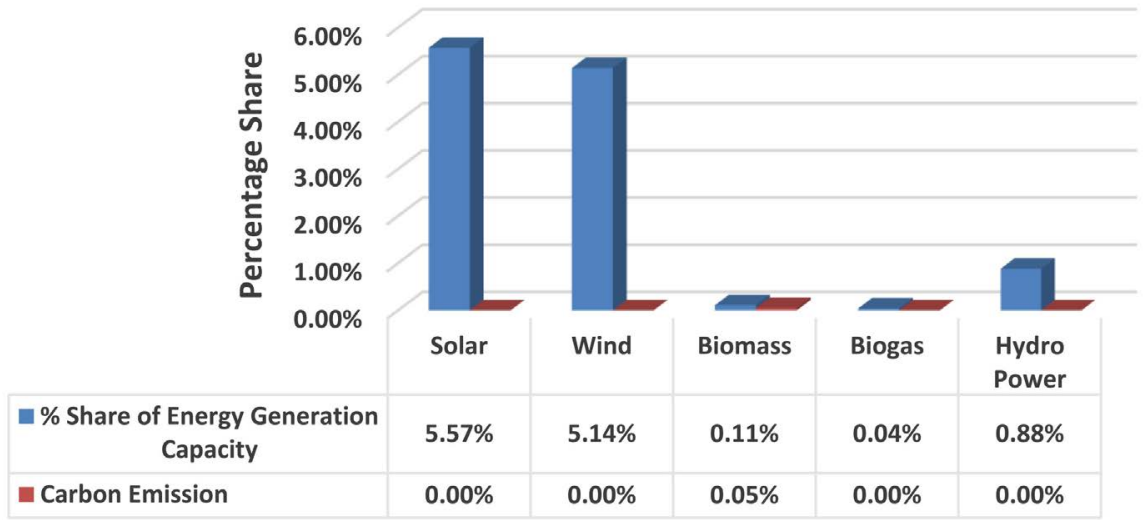

(b)

Figure 4. Percentage share of energy generation capacity (MW) of each renewable energy (RE source and relative carbon emissions in 2017 (panel (a)) and 2021 (panel (b)). Scenario 1 . 
Table 2. Percentage share of energy generation capacity (MW) of each renewable energy (RE) source, and relative carbon emissions in 2017 and 2021. Scenario 1.

\begin{tabular}{ccccc}
\hline & \multicolumn{2}{c}{ Year 2017 } & \multicolumn{2}{c}{ Year 2021 } \\
\cline { 2 - 5 } & $\begin{array}{c}\text { \% Share of energy } \\
\text { generation capacity } \\
(\mathrm{MW})\end{array}$ & $\begin{array}{c}\text { \% Share of } \\
\text { Carbon emissions } \\
\left(\mathrm{tCO}_{2} \mathrm{eq}\right)\end{array}$ & $\begin{array}{c}\text { \% Share of energy } \\
\text { generation capacity } \\
(\mathrm{MW})\end{array}$ & $\begin{array}{c}\text { \% Share of } \\
\text { Carbon emissions } \\
\left(\mathrm{tCo}_{2} \mathrm{eq}\right)\end{array}$ \\
\hline Solar & $3.35 \%$ & $0.00 \%$ & $5.57 \%$ & $0.00 \%$ \\
Wind & $1.36 \%$ & $0.00 \%$ & $5.14 \%$ & $0.00 \%$ \\
Biomass & $0.03 \%$ & $0.01 \%$ & $0.11 \%$ & $0.05 \%$ \\
Biogas & $0.03 \%$ & $0.00 \%$ & $0.04 \%$ & $0.00 \%$ \\
Hydro Power & $1.25 \%$ & $0.00 \%$ & $0.88 \%$ & $0.00 \%$ \\
\hline
\end{tabular}

It is obvious that solar power contributes the highest percentage share of energy generation capacity in the baseline year. Energy generation capacity by solar power increases by a share of $2.22 \%$ by 2021 . Wind power grows by a share of $3.78 \%$, and hydropower declines in the projected year. Biogas and Biomass only have a small percentage share of energy generation capacity. Biomass does increase 3 -fold in 2021 but it is the only source of RE with carbon output and this also increases 5-fold from 2017 to 2021.

\subsection{Scenario 2: Energy Generation Capacity Using Imports as Coal}

In Scenario 2 we analyzed the PMSP-16 values using coal as the import model. Imported coal is compared along with indigenous coal, indigenous oil, and indigenous gas. The sum of energy generation capacity from indigenous coal and imported oil, create total energy generation capacity from coal. Likewise, the sum of carbon emission output from indigenous coal and imported coal, make up the total carbon emission output for coal. Within-year total energy generation capacity and carbon emission output are shown in the bottom row, and the total energy generation capacity and carbon emission output over the total five year-period for each energy source and their percentage share are shown in the last 4 rows (Table 3 ).

Figure 5 then illustrates each FF source and total combined RE sources in Scenario 2.

Energy generation capacity from coal imports in the PSMP-16 remain the same from year to year, so there is no difference in the imported total energy generation capacity output from imports across the 5-year study trajectory in Scenario 1 compared to Scenario 2. Total carbon emission output by total coal sources does change across the trajectory. In Scenario 2 total coal contributes to $50,540,382 \mathrm{tCO}_{2}$ eq with imported and indigenous coal providing 22,863,600 $\mathrm{tCO}_{2} \mathrm{eq}$ and 27,676,782 $\mathrm{tCO}_{2} \mathrm{eq}$, respectively. In Scenario 1 imported oil provides more carbon output $\left(145,521,822 \mathrm{tCO}_{2} \mathrm{eq}\right)$ and this is due to the high percentage share of energy capacity and carbon emission output from indigenous oil. Therefore, holding imports stable, we can show that energy generation capacity by indigenous coal is lower and releases lower levels of carbon than that of oil. 
Table 3. Energy generation capacity output (MW) and carbon emission from each FF source and Total RE resources combined over the 5-year trajectory (2017-2021). Table illustrates scenario 2 which accounts for imports as coal.

\begin{tabular}{|c|c|c|c|c|c|c|c|c|c|c|c|c|c|c|}
\hline \multirow{3}{*}{$\begin{array}{c}\text { Scenario } 2 \\
\text { Coal Imports }\end{array}$} & \multicolumn{2}{|c|}{2017} & \multicolumn{2}{|r|}{2018} & \multicolumn{2}{|r|}{2019} & \multicolumn{2}{|r|}{2020} & \multicolumn{2}{|c|}{2021} & \multicolumn{4}{|c|}{$\begin{array}{c}\text { TOTAL OVER } \\
\text { 2017-2021 TRAJECTORY }\end{array}$} \\
\hline & \multirow{2}{*}{ MW } & $\mathrm{CE}$ & \multirow{2}{*}{ MW } & $\mathrm{CE}$ & \multirow{2}{*}{ MW } & $\mathrm{CE}$ & \multirow{2}{*}{ MW } & $\mathrm{CE}$ & \multirow{2}{*}{ MW } & $\mathrm{CE}$ & \multirow{2}{*}{$\begin{array}{l}\text { Total } \\
\text { MW }\end{array}$} & \multirow{2}{*}{$\begin{array}{l}\% \text { of } \\
\text { MW }\end{array}$} & \multirow{2}{*}{$\begin{array}{c}\text { Total } \\
\mathrm{TCO}_{2} \mathrm{eq}\end{array}$} & \multirow{2}{*}{$\begin{array}{c}\% \text { of } \\
\mathrm{TCO}_{2} \text { eq }\end{array}$} \\
\hline & & $\left(\mathrm{tCO}_{2} \mathrm{eq}\right)$ & & $\left(\mathrm{tCO}_{2} \mathrm{eq}\right)$ & & $\left(\mathrm{tCO}_{2} \mathrm{eq}\right)$ & & $\left(\mathrm{tCO}_{2} \mathrm{eq}\right)$ & & $\left(\mathrm{tCO}_{2} \mathrm{eq}\right)$ & & & & \\
\hline Total coal & 1685 & $6,642,270$ & 1959 & $7,722,378$ & 2619 & $10,324,098$ & 2619 & $10,324,098$ & 3939 & $15,527,538$ & 12,821 & 11.20 & $50,540,382$ & 16.41 \\
\hline $\begin{array}{c}\text { Indigenous } \\
\text { Coal }\end{array}$ & 525 & $2,069,550$ & 799 & $3,149,658$ & 1459 & $5,751,378$ & 1459 & $5,751,378$ & 2779 & $10,954,818$ & 7021 & 6.13 & $27,676,782$ & 8.99 \\
\hline $\begin{array}{l}\text { Imported } \\
\text { Coal }\end{array}$ & 1160 & $4,572,720$ & 1160 & $4,572,720$ & 1160 & $4,572,720$ & 1160 & $4,572,720$ & 1160 & $4,572,720$ & 5800 & 5.07 & $22,863,600$ & 7.43 \\
\hline $\begin{array}{c}\text { Indigenous } \\
\text { Gas }\end{array}$ & 10,001 & $24,793,279$ & 10,001 & $24,793,279.08$ & 10413 & $25,814,660$ & 11,226 & $27,830,152.08$ & 11226 & $27,830,152$ & 52,867 & 46.19 & $131,061,522$ & 42.56 \\
\hline $\begin{array}{l}\text { Indigenous } \\
\text { Oil }\end{array}$ & 5728 & $19,067,366$ & 8047 & $26,786,853.60$ & 8047 & $26,786,853.6$ & 8047 & $26,786,853.6$ & 8047 & $26,786,854$ & 37,916 & 33.13 & $126,214,781$ & 40.99 \\
\hline Solar & 621 & 0 & 858 & 0 & 1053 & 0 & 1256 & 0 & 1464 & 0 & 5252 & 4.59 & 0 & 0 \\
\hline Wind & 252.90 & 0 & 602.9 & 0 & 952.9 & 0 & 1152.9 & 0 & 1352.9 & 0 & 4314.5 & 3.77 & 0 & 0 \\
\hline Biomass & 6 & 7358.4 & 12 & $14,716.8$ & 18 & $22,075.2$ & 24 & $29,433.6$ & 30 & 36,792 & 90 & 0.08 & 110,376 & 0.04 \\
\hline Biogas & 6 & 0 & 7 & 0 & 8 & 0 & 9 & 0 & 10 & 0 & 40 & 0.03 & 0 & 0 \\
\hline $\begin{array}{l}\text { Hydro } \\
\text { Power }\end{array}$ & 232 & 0 & 232 & 0 & 232 & 0 & 232 & 0 & 232 & 0 & 1160 & 1.01 & 0 & 0 \\
\hline $\begin{array}{l}\text { TOTAL } \\
\text { (in year) }\end{array}$ & $18,531.9$ & $50,510,273.4$ & $21,718.9$ & $59,317,227.48$ & $23,342.9$ & $62,947,686.8$ & $24,565.9$ & $64,970,537.28$ & $26,300.9$ & $70,181,336$ & $114,460.5$ & 100 & $307,927,061$ & 100 \\
\hline
\end{tabular}

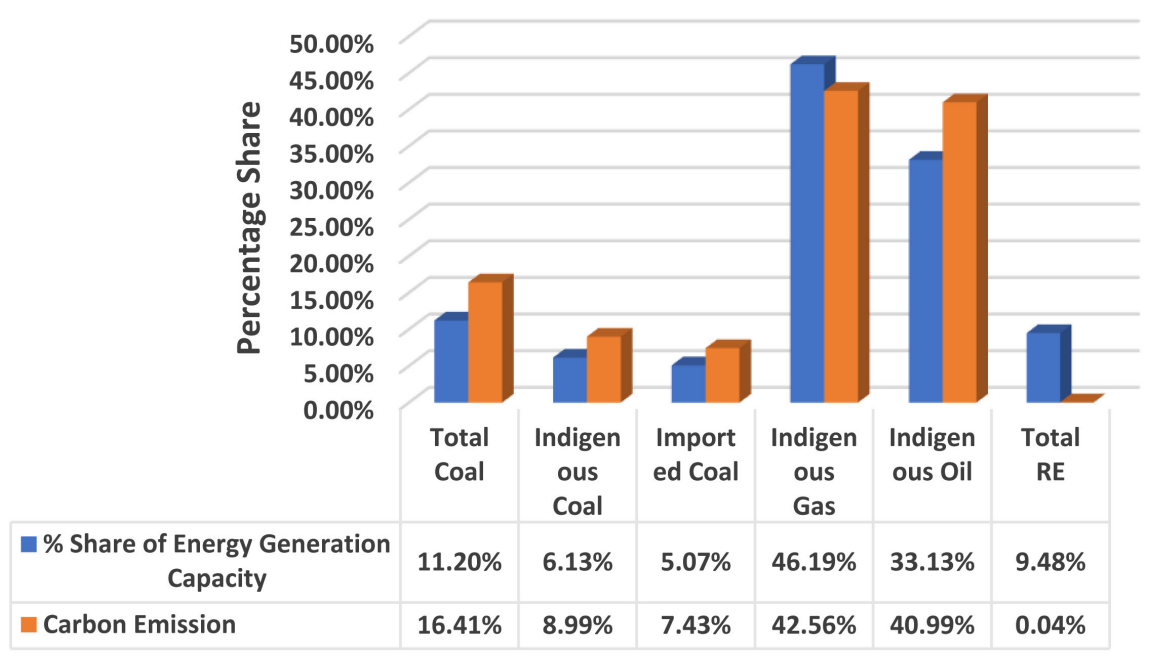

Figure 5. Percentage share of total energy generation capacity (MW) and relative carbon emissions by each fossil fuel (FF) source and all renewable energy (RE) resources combined in the 2017-2021 trajectory. Figure illustrates Scenario 2 which accounts for imports as coal.

Total energy generation capacity for RE combined over the 5 years is not different from Scenario 1 and amounts to 10,856.5 MW. Carbon emission output from $\mathrm{RE}$ is $110,376 \mathrm{tCO}_{2}$ eq over the same time-period. For illustrative purposes, the combined $\mathrm{RE}$ sources are again disaggregated into individual renewable energy sources as the percentage share of total energy generation capacity and 
percentage share of total carbon emissions from each source over 5 years and shown in Figure 6. Of the RE sources, solar power (4.59\%), then wind power (3.77\%), contribute to the greatest percentage share of total energy generation capacity.

We looked at energy generation capacity and carbon emission output from each FF source and RE in the baseline year (2017) and the projected year (2021). In Scenario 1, coal sources combined provide an extra $2254 \mathrm{MW}$ in $2021 \mathrm{com}-$ pared to 2017. There is no change in energy capacity from imported coal between the years, so it is indigenous coal that contributes for the difference in energy capacity. In 2017 , indigenous coal provides $2.83 \%$ of the share energy generation capacity and $4.10 \%$ of the share of carbon output, whereas in 2021 energy generation capacity rises to $10.57 \%$ and carbon output $15.61 \%$. In 2021 compared to 2017, an extra $1225 \mathrm{MW}$ is provided by indigenous gas and an extra 2319 MW from indigenous oil. Carbon emission output from total coal provides an extra 8,885,268 $\mathrm{tCO}_{2}$ eq in 2021 compared with 2017. As there is no difference in carbon $\mathrm{tCO}_{2}$ eq from imported coal between baseline years 2017 to project year 2021 from imported coal, it is indigenous coal that contributes to the excess carbon output in 2021. Indigenous gas accounts for an extra 3,036,873 $\mathrm{tCO}_{2}$ eq of carbon output in 2021.

Figure 7 illustrates the percentage share of energy generation capacity by each FF energy source and all the RE sources combined for Scenario 2 in 2017 (Panel (A)), the first year of the trajectory and 2021 (Panel (B)). The percentage share of carbon emissions by each energy source within this year are also illustrated. The data within each year of the trajectory are mentioned in the text.

In Scenario 2, gas shows the greatest percentage share of energy generation capacity within the baseline year (2017) which is the same as Scenario 1. However, in 2021 , at the end of the trajectory, this drops more than $10 \%$ to $42.68 \%$

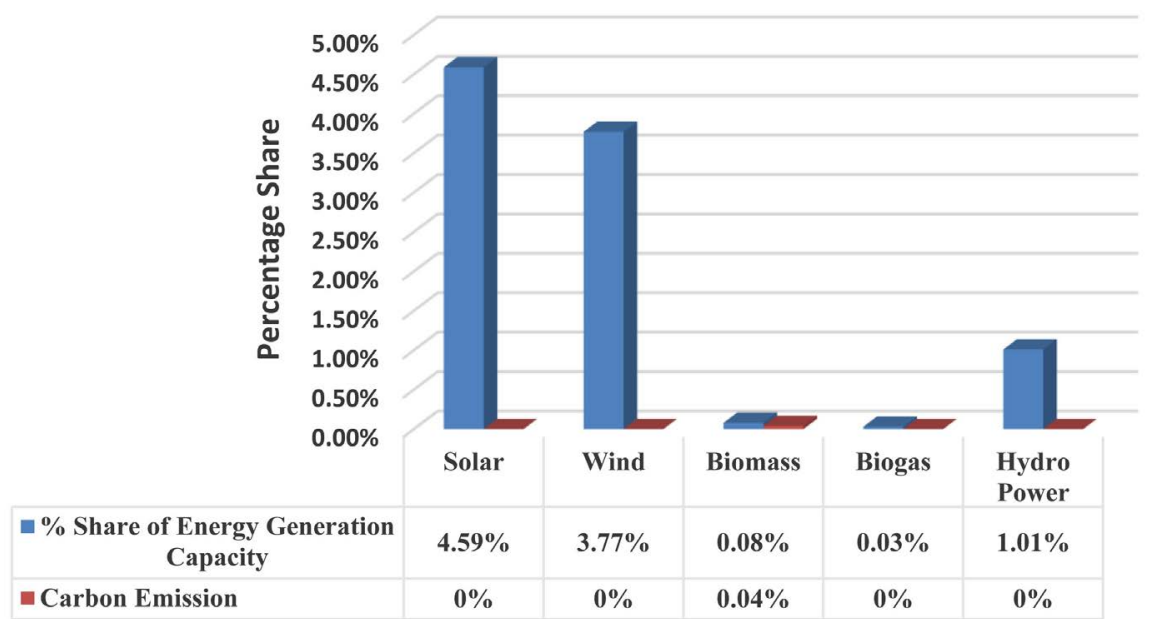

Figure 6. Percentage share of total energy generation capacity (MW) and relative carbon emissions by each renewable energy (RE) source over the entire 2017-2021 trajectory. Data are calculated from total energy generation capacity and carbon emission output from Scenario 2, which accounts for imports as coal. 


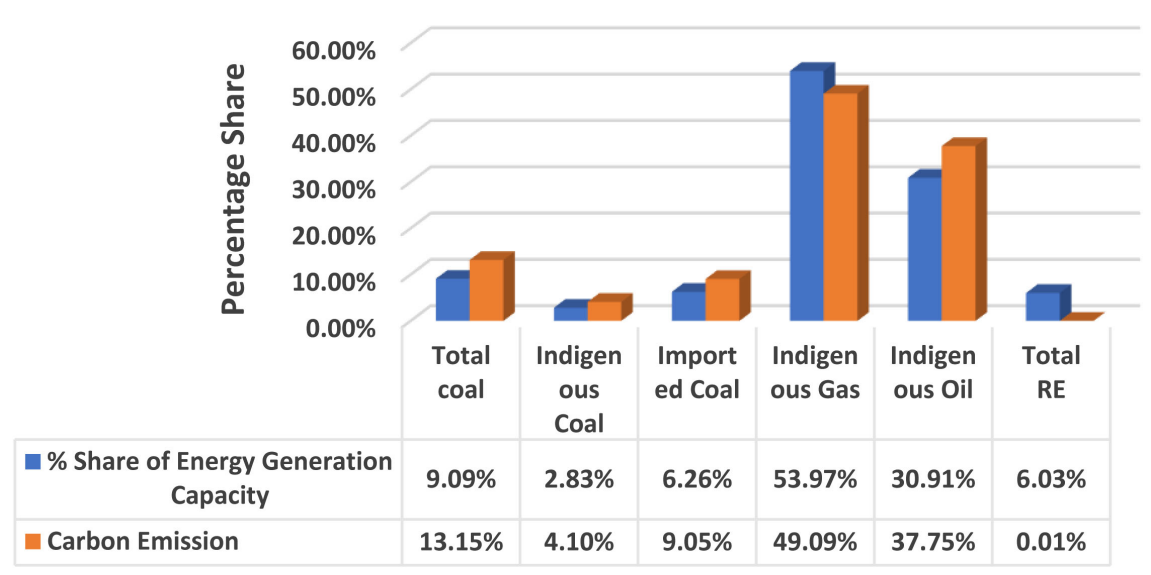

(a)

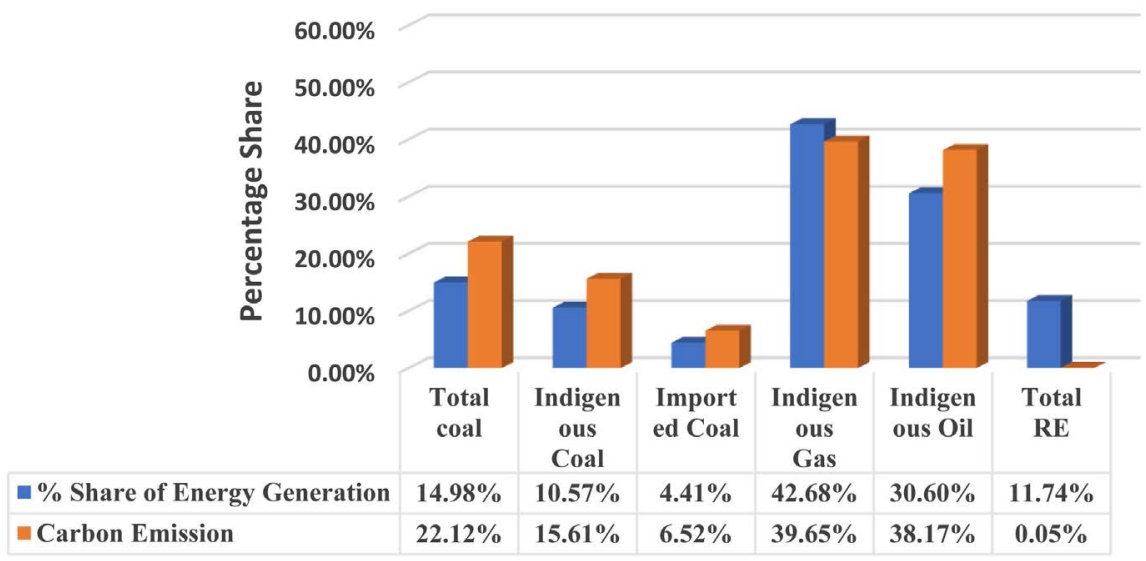

(b)

Figure 7. Percentage share of energy generation capacity (MW) of each fossil fuel (FF) and total combined renewable energy (RE) sources in Scenario 2 which accounts for imports as coal. The percentage share of carbon emissions by each energy source is also shown. The baseline year 2017 is shown in panel (a) and 2021 is shown in panel (b).

(Figure 7(a) compared with Figure 7(b)). A decrease in the percentage share of energy generation capacity by gas occurred in most years in the trajectory at (53.97\% in $2017,46.05 \%$ in $2018,44.61 \%$ in $2019,45.70 \%$ in 2020 and $42.68 \%$ in 2021). The percentage share of carbon emission output within each year also decreases over time (except for 2020), dropping approximately $10 \%$ by 2021 . This measure of carbon output is $49.09 \%$ in $2017,41.80 \%$ in $2018,41.01 \%$ in 2019 , then $42.84 \%$ and $39.65 \%$ in 2021 , respectively. Therefore, as in Scenario 1, the percentage share of carbon emissions by gas in Scenario 2 closely follows energy generation capacity output, most likely declining as percentage share of energy generation capacity decreases.

The percentage share of energy generation capacity by indigenous oil in 2021 (30.60\%) was almost the same as 2017 (30.91\%), with yearly fluctuations throughout the rest of the trajectory $(37.05 \%$ in $2018,34.5 \%$ in $2019,32.76 \%$ in 2020 , and $30.60 \%$ in 2021). This was probably due to other sources changing in the energy mix. Carbon emission output by indigenous oil contributes $37.75 \%$ of 
the share in $2017,45.16 \%$ in $2018,42.55 \%$ in $2019,41.23 \%$ in 2020 and $38.17 \%$ in 2021.

The share of energy generation capacity by all sources of coal in 2017 is $9.09 \%$. Despite some small fluctuations, the percentage share of energy generation capacity by coal rises to $14.98 \%$ by 2021 (9.02\% in 2018, to $11.22 \%$ in $2019,10.66 \%$ in 2020). Of the coal sources, indigenous coal provides $2.83 \%$ of the share of energy generation capacity in 2017 , and this source rises steadily over time $(3.68 \%$ in $2018,6.25 \%$ in 2019 and $5.94 \%$ in 2020). Notably, by 2021, the projected values rise almost 4 -fold to $10.57 \%$. Coal imports initially contributed the greater percentage share of energy generation capacity by coal sources at $6.26 \%$. However, this declines over time $(5.34 \%, 4.97 \%, 4.72 \%$ and $4.41 \% ; 2018-2021$, respectively). Therefore, the use of indigenous coal appears to take precedence in of Bangladesh within the projected study period. This is in line with the Bangladeshi government propositions introduced in the literature review.

Carbon emission output by total coal rises over the study period. In 2017, the percentage share of carbon emission output by all sources of coal amounts to $13.15 \%$. At the end of the study trajectory, the percentage share of carbon emission output from all coal sources rises to $22.12 \%(13.02 \%$ in $2018,16.40 \%$ in 2019 , and $15.89 \%$ in 2020 ). This rise is mainly due to an increase in indigenous coal. The percentage share of carbon emission output by indigenous coal is observed to rise almost 4 -fold from $4.10 \%$ in 2017 to $15.61 \%$ in 2021 . The values for indigenous coal in other years are 5.31\% in 2018, 9.14\% in 2019 and $8.85 \%$ in 2020. That indigenous coal is a factor contributing to the projected rise in carbon emission output by coal is supported by a drop in the percentage share of energy generation capacity by imported coal. The latter coal source contributes to $9.05 \%$ of the baseline year (2017) total carbon emission output, whereas by 2021 this measure was lower (6.52\%).

As in Scenario 1, the percentage chare of energy generation capacity by RE sources combined increases substantially over time. RE sources contribute $6.03 \%$ of the share of energy generation capacity in 2017, 7.88\% in 2018, 9.70\% in 2019 and $10.88 \%$ in 2020 . The share of energy generation capacity by RE in 2021 is nearly double that of the baseline year (11.74\%). There is also an increase in the percentage share of carbon emission by combined RE sources over the years, and this is sourced from biomass ( $0.01 \%$ in 2017 to $0.05 \%$ in 2021).

We next disaggregated the RE sources and quantitated energy generation capacity and carbon emissions. Results are given in Table 4 and Figure 8 (a) and Figure 8(b).

The results from Scenario 2, were the same as Scenario 1 Table 4 vs Table 2. Increases in the percentage share of RE over the trajectory was attributed to an increase in the percentage share of energy generation capacity by solar power and wind power over the trajectory (Figure $8(\mathrm{a})$ and Figure $8(\mathrm{~b})$ ).

\subsection{Percentage Equivalence Analysis}

It is of particular interest to see how carbon emissions change from each energy 
A. Dulal et al.

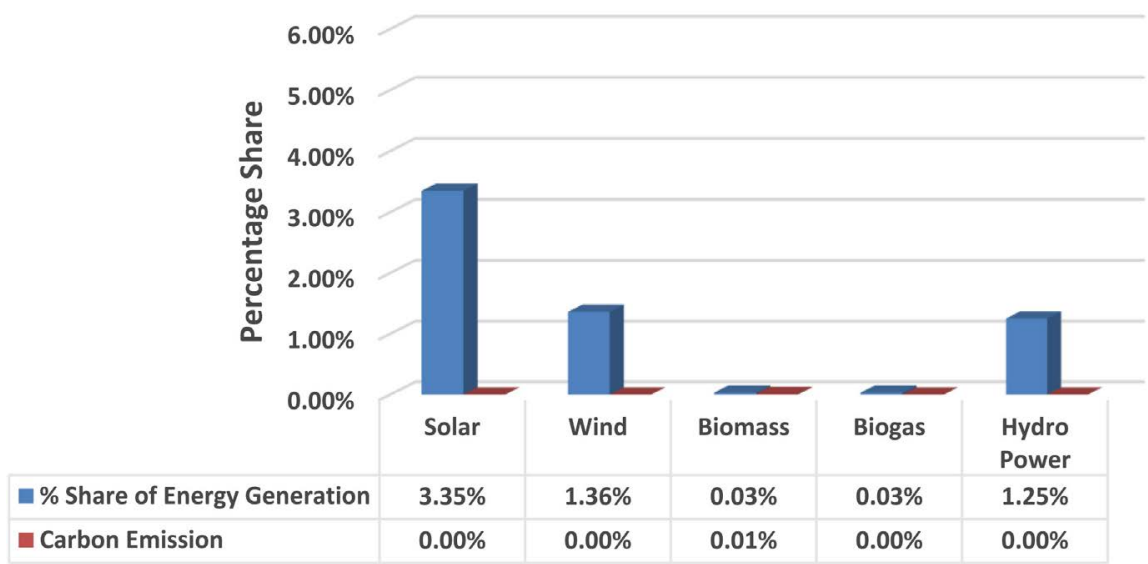

(a)

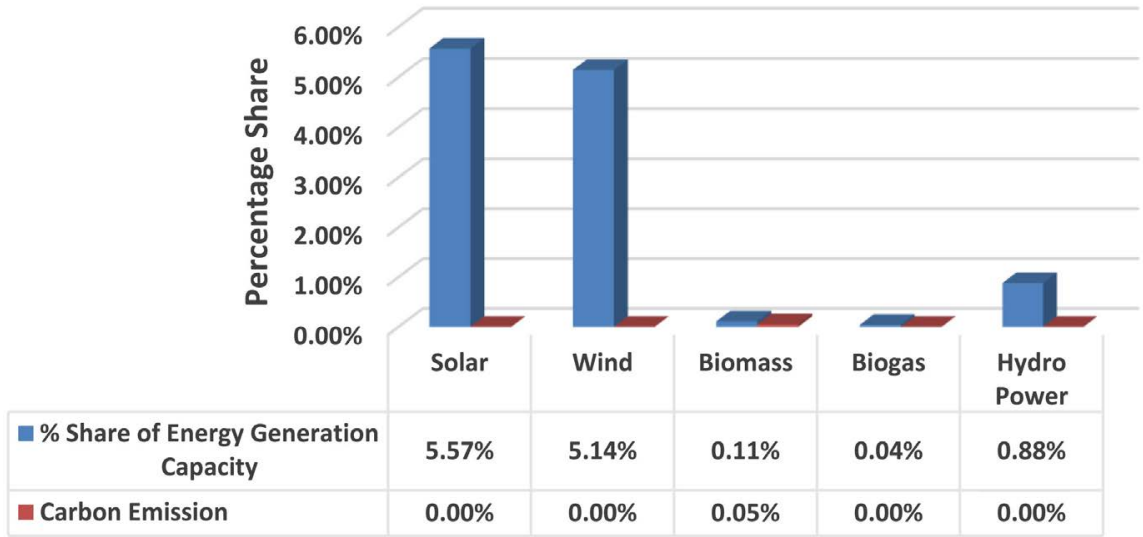

(b)

Figure 8. Percentage share of energy generation capacity (MW) of each renewable energy (RE) source and relative carbon emissions in 2017 (panel (a)) and 2021 (panel (b)). Scenario 2 .

Table 4. Percentage share of energy generation capacity (MW), and percentage share of carbon emissions by each renewable energy (RE) source in 2017 and 2021. Scenario 2.

\begin{tabular}{ccccc}
\hline & \multicolumn{3}{c}{ Year 2017} & \multicolumn{2}{c}{ Year 2021 } \\
\cline { 2 - 5 } & $\begin{array}{c}\text { \% Share of energy } \\
\text { generation capacity } \\
(\mathrm{MW})\end{array}$ & $\begin{array}{c}\text { \% Share of } \\
\text { Carbon emissions } \\
\left(\mathrm{tCO}_{2} \mathrm{eq}\right)\end{array}$ & $\begin{array}{c}\text { \% Share of energy } \\
\text { generation } \\
\text { capacity }(\mathrm{MW})\end{array}$ & $\begin{array}{c}\text { \% Share of } \\
\text { Carbon emissions } \\
\left(\mathrm{tCO}_{2} \mathrm{eq}\right)\end{array}$ \\
\hline Solar & $3.35 \%$ & $0.00 \%$ & $5.57 \%$ & $0.00 \%$ \\
Wind & $1.36 \%$ & $0.00 \%$ & $5.14 \%$ & $0.00 \%$ \\
Biomass & $0.03 \%$ & $0.01 \%$ & $0.11 \%$ & $0.05 \%$ \\
Biogas & $0.03 \%$ & $0.00 \%$ & $0.04 \%$ & $0.00 \%$ \\
Hydro Power & $1.25 \%$ & $0.00 \%$ & $0.88 \%$ & $0.00 \%$ \\
\hline
\end{tabular}

source when they each have an equal increase in energy generation capacity. We analyzed this model for Scenario 1 and Scenario 2. For Scenario 1, in which oil is accounted as an import, calculations reveal that a $1 \%$ increase in total oil, indigenous oil and imported oil energy generation capacity increases carbon emis- 
sion output by $1.25 \%$. For each of the oil sources, respectively. A $1 \%$ increase in indigenous coal-based energy generation capacity increases carbon emission output to a greater degree (1.48\%). Interestingly, a $1 \%$ in indigenous gas-based energy generation capacity results in the lowest $(0.93 \%)$ carbon emission output. A $1 \%$ increase in RE based energy generation capacity results in very little carbon emission output $(0.0042 \%)$.

In Scenario 2 which accounts for coal as an import, calculations reveal that a $1 \%$ increase in total coal, indigenous coal, and imported coal-based energy generation capacity increases carbon emission output by $1.46 \%$ for all coal sources, respectively. A $1 \%$ increase indigenous oil-based energy generation capacity causes slightly lower (1.23\%) carbon emission output. When indigenous gas-based energy generation capacity increases by $1 \%$, carbon emission output is $0.92 \%$. Therefore, in both scenarios, gas shows the lowest carbon emission output of the FF sources relative to equal increases in energy generation capacity.

In Scenario 2 a 1\% increase in RE based energy generation capacity increases carbon emission output by $0.0042 \%$, so is not different than Scenario 1. Distinctly, energy generation capacity from RE can potentially reduce a significant amount of carbon emissions if it replaces any of the FF. This is analysed further in Sections 4.3 and 4.4 .

\subsection{Emission Reduction Analysis (ER)}

Baseline carbon emissions are calculated by multiplying the combined RE sources and each individual FF and with its carbon emission intensity (CEI). Each energy source is converted to MWh. The RE project energy generation capacity is then established. The project emission was the subtracted from the $\mathrm{BE}$ to obtain the emission reduction. Afterwards, the carbon emissions reduced by $\mathrm{RE}$ from FF based energy generation is presented as the ER. Results for each FF type in Scenario 1 are presented in Table 5. These include oil-based imports, indigenous oil, the other indigenous imports, coal, and gas.

In Scenario 1, indigenous gas has the highest BE of carbon in 2017 $\left(1,487,596.74 \mathrm{tCO}_{2}\right.$ eq), followed by indigenous oil $\left(1,144,041.98 \mathrm{tCO}_{2}\right.$ eq). Imported oil attributes to lower $\mathrm{BE}$ levels of carbon although indigenous coal has the lowest $\mathrm{BE}$ carbon emission (124,173 $\left.\mathrm{tCO}_{2} \mathrm{eq}\right)$. The findings are primarily governed by each energy sources CEI. These are $0.9 \mathrm{kWh} 0.76 \mathrm{KWh}$ and $0.57 \mathrm{kWh}$ for coal, oil, and gas, respectively. In 2021, indigenous gas again shows the highest $\mathrm{BE}\left(3,339,618.25 \mathrm{tCO}_{2} \mathrm{eq}\right)$ and the increase in $\mathrm{BE}$ of indigenous oil increased almost 3-fold. Indigenous coal shows the lowest BE carbon emissions in 2017 and this increases over 10 -fold over the 5-year trajectory so that in 2021 , the $\mathrm{BE}$ value of carbon output from indigenous coal is $1314578.16 \mathrm{tCO}_{2}$ eq. This latter finding highlights the massive growth in indigenous coal use. Except for biomass, the RE sources in the present study do not show carbon output. The CEI from biomass is only $0.28 \mathrm{kWh}$. In this regard, the sum of RE CEI values is low. Therefore, there are only minor changes in ER by RE. 
Table 5. Calculation of baseline (BE) of carbon from fossil fuel sources, projected emission (PE) of renewable energy RE) sources and the effect of carbon emission reduction (ER) for each year in the study time-period. Scenario 1: Oil based.

\begin{tabular}{|c|c|c|c|c|c|}
\hline Resource & 2017 & 2018 & 2019 & 2020 & 2021 \\
\hline Imp. Oil (MWH) & $5,080,800$ & $5,080,800$ & $5,080,800$ & $5,080,800$ & $5,080,800$ \\
\hline Ind. Oil (MWH) & $25,088,640$ & $35,245,860$ & $35,245,860$ & $35,245,860$ & $35,245,860$ \\
\hline Ind. gas (MWH) & $43,804,380$ & $43,804,380$ & $45,608,940$ & $49,169,880$ & $49,169,880$ \\
\hline Ind. coal (MWH) & $2,299,500$ & $3,499,620$ & $6,390,420$ & $6,390,420$ & $12,172,020$ \\
\hline $\mathrm{RE} \%$ & $6 \%$ & $8.0 \%$ & $10 \%$ & $11 \%$ & $12 \%$ \\
\hline Imp. Oil Baseline (MWH) & 304,848 & 406,464 & 508,080 & 558,888 & 609,696 \\
\hline Ind. Oil Baseline (MWH) & $1,505,318.4$ & $2,819,668.8$ & $3,524,586$ & $3,877,044.6$ & $4,229,503.2$ \\
\hline Ind. gas baseline (MWH) & $2,628,262.8$ & $3,504,350.4$ & $4,560,894$ & $5,408,686.8$ & $5,900,385.6$ \\
\hline Ind. Coal baseline (MWH) & 137,970 & $279,969.6$ & 639,042 & $702,946.2$ & $146,0642.4$ \\
\hline $\mathrm{BE}\left(\mathrm{Imp}\right.$. Oil tCO $\left.\mathrm{tC}_{2} \mathrm{eq}\right)$ & $231,684.48$ & $308,912.64$ & $386,140.8$ & $424,754.88$ & $463,368.96$ \\
\hline $\mathrm{BE}$ (Ind. Oil tCO${ }_{2} \mathrm{eq}$ ) & $1,144,041.98$ & $2,142,948.288$ & $2,678,685.36$ & $2,946,553.9$ & $3,214,422.43$ \\
\hline $\mathrm{BE}$ (Ind. Gas $\mathrm{tCO}_{2} \mathrm{eq}$ ) & $1,487,596.74$ & $1,983,462.326$ & $2,581,466.004$ & $3,061,316.73$ & $3,339,618.25$ \\
\hline $\mathrm{BE}$ (Ind. Coal tCO $\mathrm{CO}_{2} \mathrm{eq}$ ) & 124,173 & $251,972.64$ & $575,137.8$ & $632,651.58$ & $1,314,578.16$ \\
\hline $\begin{array}{c}\mathrm{PE} \text { (RE. } \mathrm{CO}_{2} \text { emission) } \\
\left.\mathrm{tCO}_{2} \mathrm{eq}\right)\end{array}$ & 7358.4 & $14,716.8$ & $22,075.2$ & $29,433.6$ & 36,792 \\
\hline ER (Imp. Oil tCO ${ }_{2}$ eq) & $224,326.08$ & $294,195.84$ & $364,065.6$ & $395,321.28$ & $426,576.96$ \\
\hline ER (Ind. Oil tCO${ }_{2}$ eq) & $1,136,683.58$ & $2,128,231.488$ & $2,656,610.16$ & $2,917,120.3$ & $3,177,630.43$ \\
\hline $\mathrm{ER}$ (Ind. Gas $\mathrm{tCO}_{2} \mathrm{eq}$ ) & $1,480,238.34$ & $1,968,745.526$ & $2,559,390.804$ & $3,031,883.13$ & $3,302,826.25$ \\
\hline ER (Ind. coal tCO ${ }_{2}$ eq) & $116,814.6$ & $237,255.84$ & $553,062.6$ & $603,217.98$ & $1,277,786.16$ \\
\hline
\end{tabular}

We next looked at the ER for Scenario 2. These values included imported oil, and the indigenous FF's oil, coal, and gas. The results are presented in Table 6.

In Scenario 2, the values for BE in 2017 are similar to those of Scenario 1, the exception being imported coal. The BE of imported coal in 2017 is $274,363.2$ $\mathrm{tCO}_{2}$ eq whereas imported oil for the same time-period in Scenario 1 is less $\left(231,684.48 \mathrm{tCO}_{2} \mathrm{eq}\right)$. The higher values of imported coal across the study period are primarily attributed to the higher CEI of coal. Again, the ER values by RE in Scenario 2 are not extraordinarily different from $\mathrm{BE}$ values.

\subsection{Sensitivity Analysis}

Sensitivity analysis was conducted on emission reduction results. The average baseline emission and average emission reduction stand for the mixed energy baseline emissions and emission reduced by RE, respectively, when RE is modelled into the system at equal energy generation capacity. Sensitivity analysis was conducted for both scenarios in the first year (2017) and projected year (2021) of the trajectory. 
Table 6. Calculation of baseline (BE) of carbon from fossil fuel sources, projected emission $(\mathrm{PE})$ of renewable energy (RE) sources and the effect of carbon emission reduction (ER) for each year in the study time-period. Scenario 2: Coal based.

\begin{tabular}{|c|c|c|c|c|c|}
\hline Resource & 2017 & 2018 & 2019 & 2020 & 2021 \\
\hline Imp. coal (MWH) & $5,080,800$ & $5,080,800$ & $5,080,800$ & $5,080,800$ & $5,080,800$ \\
\hline Ind. coal (MWH) & $2,299,500$ & $3,499,620$ & $6,390,420$ & $6,390,420$ & $12,172,020$ \\
\hline Ind. Gas (MWH) & $43,804,380$ & $43,804,380$ & $45,608,940$ & $49,169,880$ & $49,169,880$ \\
\hline Ind. Oil (MWH) & $25,088,640$ & $35,245,860$ & $35,245,860$ & $35,245,860$ & $35,245,860$ \\
\hline RE\% & $6 \%$ & $8 \%$ & $10 \%$ & $11 \%$ & $12 \%$ \\
\hline $\begin{array}{l}\text { Imp. coal Baseline } \\
(\mathrm{MWH})\end{array}$ & 304,848 & 406,464 & 508,080 & 558,888 & 609,696 \\
\hline $\begin{array}{l}\text { Ind. coal Baseline } \\
\text { (MWH) }\end{array}$ & 137,970 & $279,969.6$ & 639,042 & $702,946.2$ & $1,460,642.4$ \\
\hline $\begin{array}{l}\text { Ind. gas baseline } \\
\text { (MWH) }\end{array}$ & $2,628,262.8$ & $3,504,350.4$ & $4,560,894$ & $5,408,686.8$ & $5,900,385.6$ \\
\hline $\begin{array}{l}\text { Ind. oil baseline } \\
\text { (MWH) }\end{array}$ & $1,505,318.4$ & $2,819,668.8$ & $3,524,586$ & $3,877,044.6$ & $4,229,503.2$ \\
\hline $\begin{array}{c}\mathrm{BE} \\
\left.\text { (Imp. coal tCO } \mathrm{tC}_{2} \mathrm{eq}\right)\end{array}$ & $274,363.2$ & $365,817.6$ & 457,272 & $502,999.2$ & $548,726.4$ \\
\hline $\begin{array}{c}\mathrm{BE} \\
\text { (Ind. Coal tCO }{ }_{2} \mathrm{eq} \text { ) }\end{array}$ & 124,173 & $251,972.64$ & $575,137.8$ & $632,651.58$ & $1,314,578.16$ \\
\hline $\begin{array}{c}\mathrm{BE} \\
\text { (Ind. Gas tCO } \mathrm{CO}_{2} \mathrm{eq} \text { ) }\end{array}$ & $1,487,596.745$ & $1,983,462.326$ & $2,581,466.004$ & $3,061,316.729$ & $3,339,618.25$ \\
\hline $\begin{array}{c}\mathrm{BE} \\
\text { (Ind. oil } \mathrm{tCO}_{2} \mathrm{eq} \text { ) }\end{array}$ & $1,144,041.984$ & $2,142,948.288$ & $2,678,685.36$ & $2,946,553.896$ & $3,214,422.432$ \\
\hline $\begin{array}{c}\text { PE (RE. } \mathrm{CO}_{2} \text { emission) } \\
\left.\mathrm{tCO}_{2} \mathrm{eq}\right)\end{array}$ & 7358.4 & $14,716.8$ & $22,075.2$ & $29,433.6$ & 36,792 \\
\hline $\begin{array}{c}\text { ER } \\
\left.\text { (Imp. coal tCO }{ }_{2} \mathrm{eq}\right)\end{array}$ & $267,004.8$ & $351,100.8$ & $435,196.8$ & $473,565.6$ & $511,934.4$ \\
\hline $\begin{array}{c}\text { ER } \\
\text { (Ind. coal tCO } \text { teq }_{2} \text { ) }\end{array}$ & $116,814.6$ & $237,255.84$ & $553,062.6$ & $603,217.98$ & $1,277,786.16$ \\
\hline $\begin{array}{c}\text { ER } \\
\text { (Ind. Gas } \mathrm{tCO}_{2} \mathrm{eq} \text { ) }\end{array}$ & $1,480,238.345$ & $1,968,745.526$ & $2,559,390.804$ & $3,031,883.129$ & $3,302,826.25$ \\
\hline $\begin{array}{c}\text { ER } \\
\text { (Ind. oil } \mathrm{tCO}_{2} \mathrm{eq} \text { ) }\end{array}$ & $1,136,683.584$ & $2,128,231.488$ & $2,656,610.16$ & $2,917,120.296$ & $3,177,630.432$ \\
\hline
\end{tabular}

Results for Scenario 1 in 2017 are illustrated in Figure 9(a) and Figure 9(b). Results in Figure 9(a) shows the baseline carbon emission effect and Figure 9(b) shows the carbon ER effect on each FF after RE is modelled into the equation and used at equal generation capacity as the FF it replaces. Values given are at -0.25 and +0.25 which are random numbers generated in sensitivity modelling using one factor at a time. Is it observed that at $-0.25 \%$ and $+0.25 \%$, the $\mathrm{BE}$ of carbon is significantly higher from indigenous gas-based power and then from indigenous oil. The lowest baseline carbon emissions came from imported 


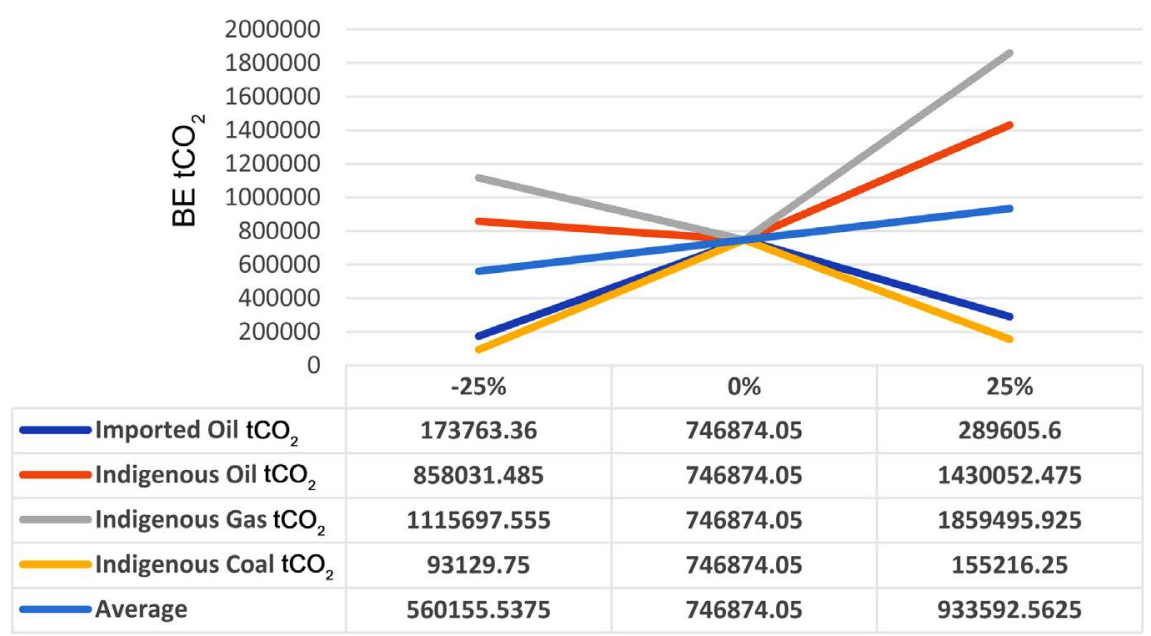

(a)

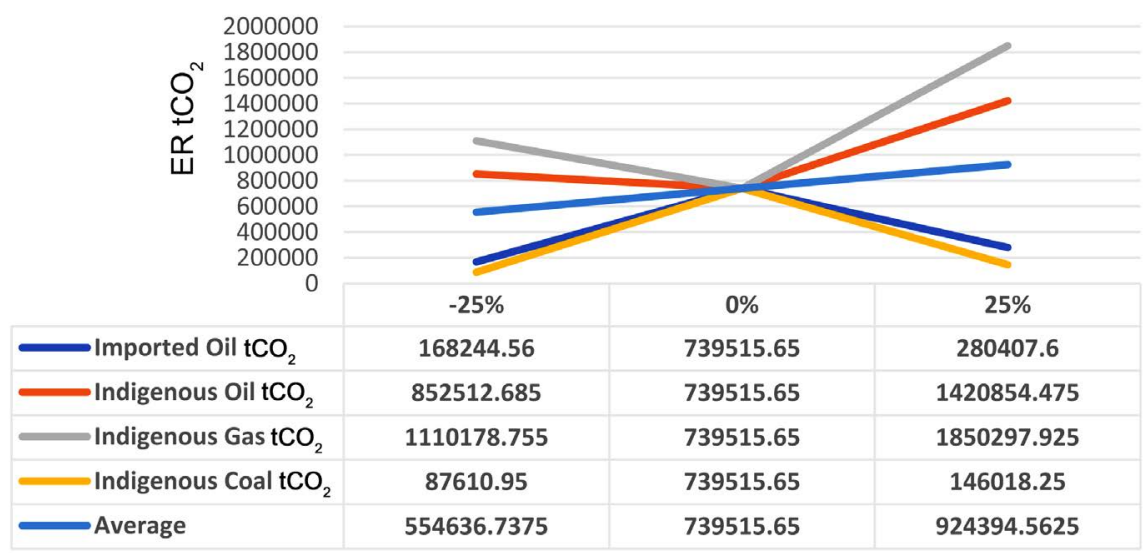

(b)

Figure 9. (a) and (b) Sensitivity analysis for each FF variable in scenario 1 in 2017 using oil as an import. Panel (a) shows baseline emission (BE) of carbon output from each FF. Panel B shows carbon emission reduction (ER) by RE on each FF after RE is modelled into the equation and used at equal generation capacity as the FF it replaces. Values given are at -0.25 and +0.25 which are random numbers generated in sensitivity modelling using one factor at a time.

oil and indigenous coal, respectively. Figure 9(b) clarifies Section 4.4 that RE has no effect on carbon ER for any of the FF and carbon output remains very similar to BE levels.

\section{Scenario 1: 2017}

In 2021, (Figure 10(a) and Figure 10(b)), sensitivity analysis shows that BE carbon levels (Figure 10(a)) from gas power generation and indigenous oil are very similar and carbon output from both sources is higher than 2017. On the other-hand imported oil is significantly lower than average emissions, and then indigenous coal.

\section{Scenario 1: 2021}

By observing Figure 10(b), one can see that there is clearly no effect of RE on reducing carbon emission output from any of the FF. 


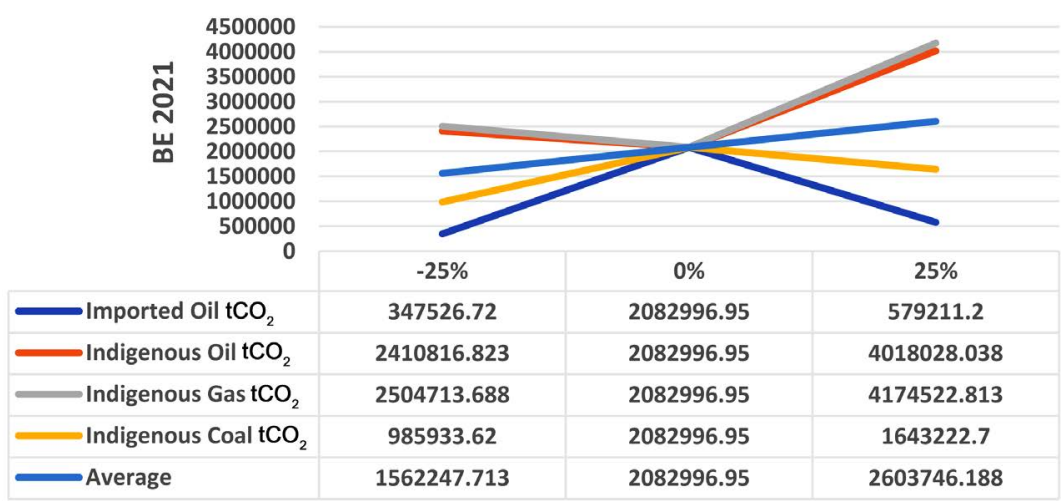

(a)

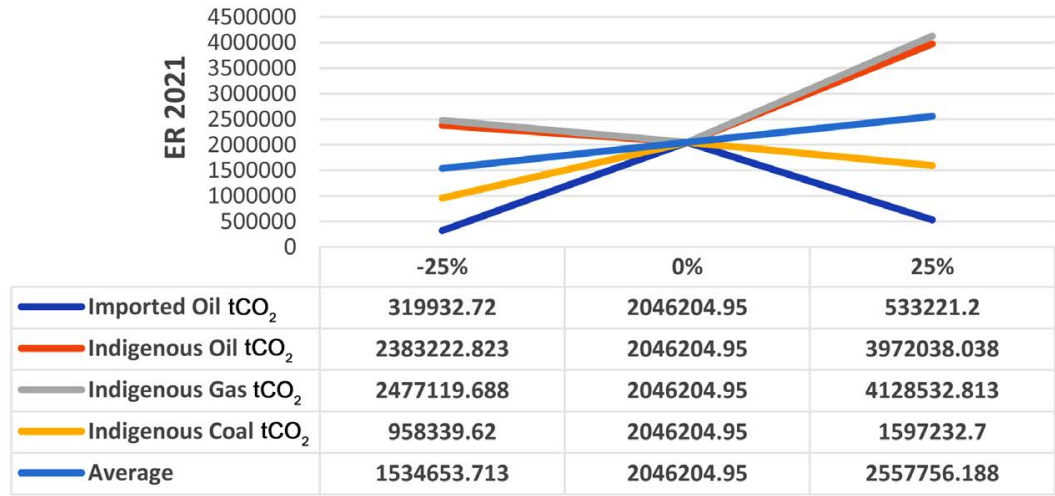

(b)

Figure 10. (a) and (b) Sensitivity analysis for each FF variable in scenario 1 in 2021 using oil as an import. Panel (a) shows baseline emission (BE) of carbon output from each FF. Panel $\mathrm{B}$ shows carbon emission reduction (ER) by RE on each FF after RE is modelled into the equation and used at equal generation capacity as the FF it replaces. Values given are at -0.25 and +0.25 which are random numbers generated in sensitivity modelling using one factor at a time.

The procedure is repeated for Scenario 2. Figure 11(a) illustrates the sensitivity results for the baseline carbon emission effect and Figure 11(b) shows carbon ER by RE on each FF when RE is modelled to replace a FF one factor at a time. In 2017, gas power generation shows the highest baseline levels of carbon emission output and indigenous oil is also higher than average emissions (Figure 11(a)). Indigenous and imported coal, respectively, show significantly less baseline emissions of carbon output. RE has no effect of reducing carbon output from any of the fossil fuels (Figure 11(b)).

\section{Scenario 2: 2017}

In 2021, random number generation in the sensitivity analysis shows that gas power generation and indigenous oil show much higher BE carbon levels than 2017 (Figure 12(a)), and they are both higher than average emissions. BE from indigenous oil being almost the same as gas. Imported coal has the lowest BE and indigenous coal is also lower than average emissions. Again, RE has no effect on carbon ER (Figure 12(b)).

Scenario 2: 2021 


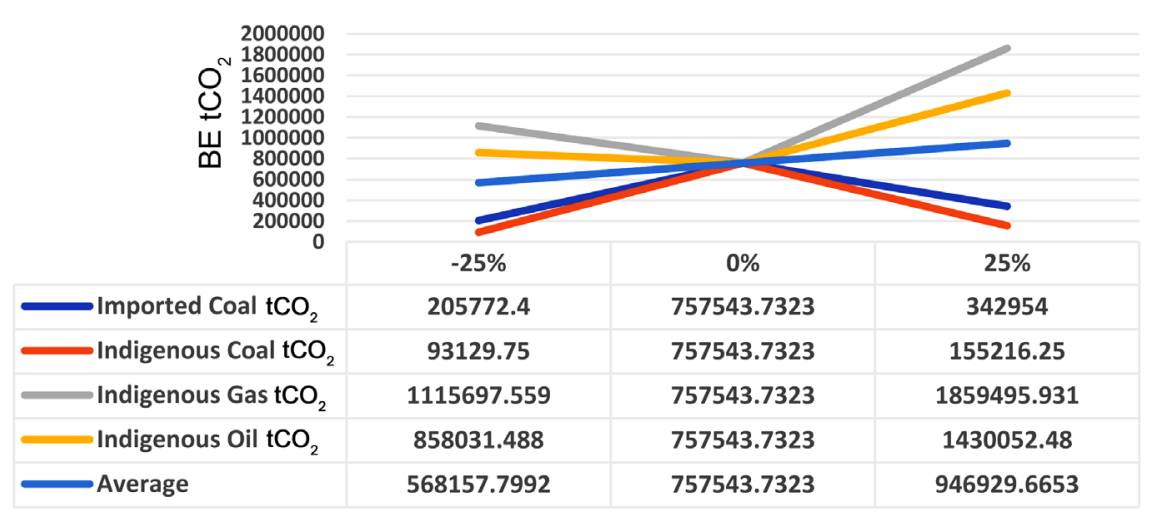

(a)

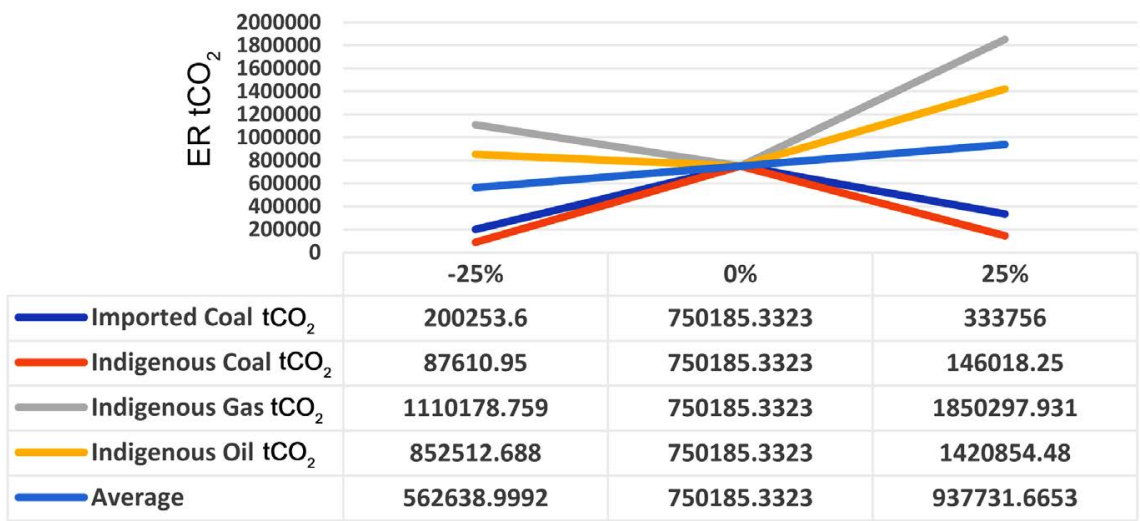

(b)

Figure 11. (a) and (b) Sensitivity analysis for each FF variable in scenario 2 in 2017 using coal as an import. Panel (a) shows baseline emission (BE) of carbon output from each FF. Panel $\mathrm{B}$ shows carbon emission reduction (ER) by RE on each FF after RE is modelled into the equation and used at equal generation capacity as the FF it replaces. Values given are at -0.25 and +0.25 which are random numbers generated in sensitivity modelling using one factor at a time.

\section{Conclusions}

The transition from FF to RE has significant environmental consequences for carbon emission reduction. Countries undergoing rapid urbanization and industrialization have the dilemma of meeting energy needs for economic development in the face of tighter controls for carbon mitigation. Economic and industrial growth can potentiate energy demands in short term scenarios. Bangladesh is a good model of a country undergoing rapid urbanization and economic development. Bangladesh is one of the least developed countries in the world, but also among the most populous in terms of density [44]. In just the previous decade, $40 \%$ of people lived below the upper poverty line and $25 \%$ live below it [45]. The country is also undergoing enormous challenges is terms of energy capacity. However, to reduce poverty in this country more energy production is needed to supply the on grid and off grid areas.

The current study addresses the best scenario for maximizing energy potential and mitigating carbon emissions in a mixed energy system. First, we disaggre 


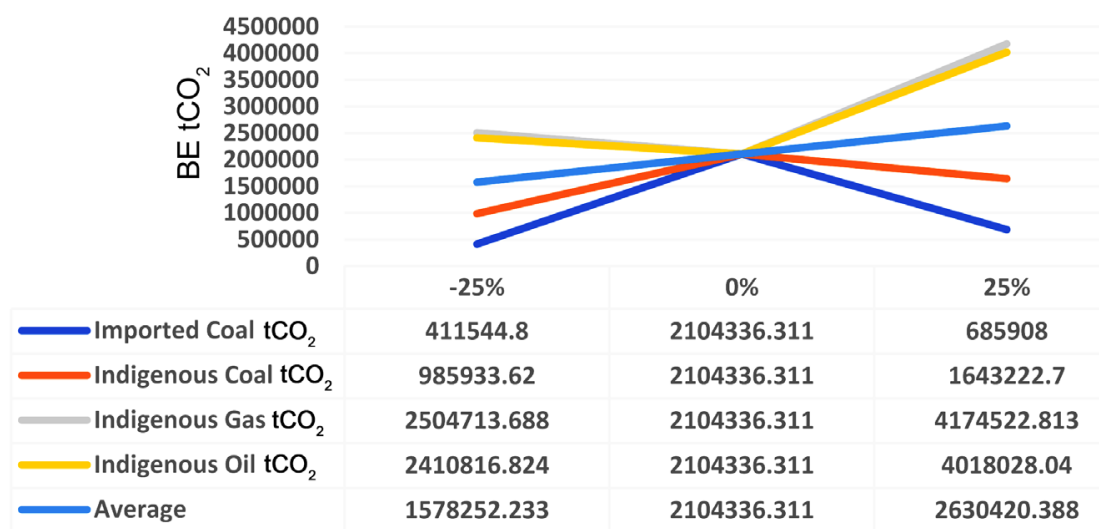

(a)

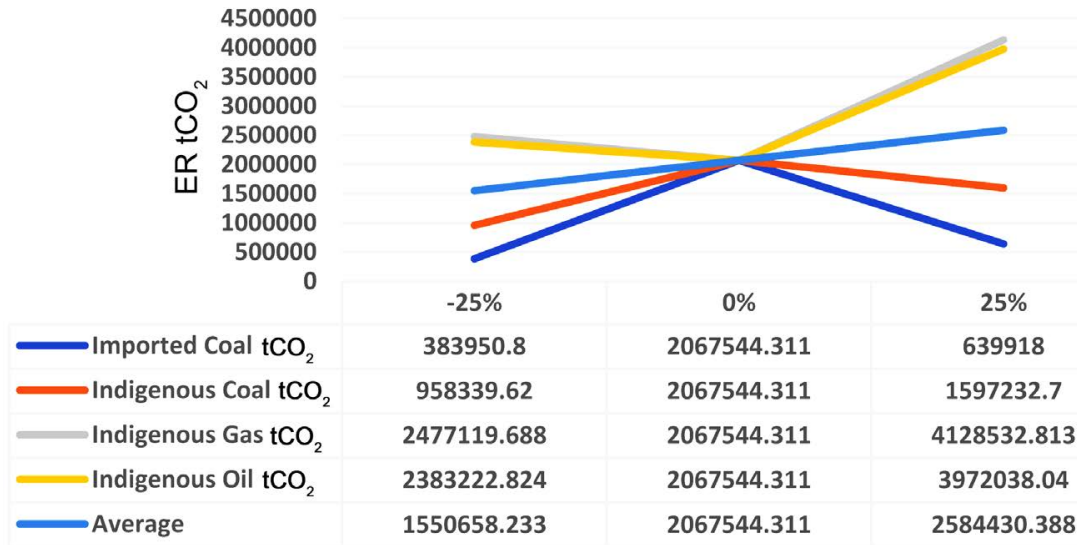

(b)

Figure 12. (a) and (b) Sensitivity analysis for each FF variable in scenario 2 in 2021 using coal as an import. Panel A shows baseline emission (BE) of carbon output from each FF. Panel $B$ shows carbon emission reduction (ER) by RE on each FF after RE is modelled into the equation and used at equal generation capacity as the FF it replaces. Values given are at -0.25 and +0.25 which are random numbers generated in sensitivity modelling using one factor at a time.

gate the different energy resources used in Bangladesh and measure short term energy production and subsequent carbon emission output in the country over 5 years. Percentage equivalence analysis is used to equalize all fuel sources and observe result in carbon emissions relative to equal increases in energy generation capacity. Next, we model the replacement of each fossil fuel one at a time with RE. In this model the installed RE must be at the same energy capacity as that of the FF it is replacing. The results from the E-IO analysis in this study show that energy generation capacity in Bangladesh increases over the short term 5-year trajectory taken from the PSMP-2016. The percentage share of energy generation from gas and oil, in particular, indigenous oil, are the main contributors to energy generation capacity. This is the case whether imports are either oil or coal and is illustrated when energy sources are combined as a whole over the 5 years. When energy sources are disaggregated and analysed by year, energy generation by gas declines in both import scenarios, and oil remains 
fairly stable. Furthermore, such disaggregation of fuel sources by year illustrates that coal and RE are the main sources of growing energy generation in the short term time-period. Moreover, the percentage share of energy generation capacity by $\mathrm{RE}$ in Bangladesh is at least equal to the percentage share by coal in this country. It is obvious from the study that gas and indigenous oil mainly contribute to the growth in energy generation capacity, however, the study shows that carbon emission output from FF sources also increases alongside energy generation capacity in Bangladesh. On the other-hand, RE contributes negligibly to this carbon output. However, our results show that even though energy generation capacity from RE, notably solar and wind power, grows in the short term in Bangladesh, energy generation capacity and carbon emission output by coal can potentially rapidly catch up to gains made by clean energy.

Wind and solar power grow significantly in the short term trajectory. As Bangladesh is rich in renewable resources and ideally placed on the globe to capture energy sources such as hydropower, wind and solar, increasing awareness and practices in RE technology can be the cornerstone for carbon emission mitigation in this Bangladesh. Our results, however, show that in the short term $\mathrm{RE}$ in its present state, cannot reduce the massive output of carbon emissions from FF. Therefore, there needs to be further research into improving the energy generation capacity of RE resources for long term prospects. It is also more likely that a number of different practices need to be in place along with enrichment of renewable and sustainable energy to reduce carbon output in Bangladesh. Some examples are improved ecological and energy management techniques, carbon capture, and financial features such as employing carbon tariffs as well as more commitment by stakeholders into augmenting RE and decreasing FF use. All need to be in place and work conjunctively with enhanced RE technologies to mitigate carbon output in the long term. The short-term elimination of FF is unfeasible in this country in the short-term as it contributes the greatest share of energy generation in the energy mix. This is a point that is reinforced by finding in the current study. Thus, energy policy needs to centre on how to reduce carbon emissions in a mixed energy system whilst using multiple measures to keep up with energy demand. A plausible measure that can be implemented is a scenario where at least one of the FF sources is transitioned out of the energy sector and replaced with improved installation of RE technology. Our results from percentage equivalence analysis show that in both scenarios, despite having the highest energy generation capacity and carbon output, gas shows the lowest carbon emission output of the FF sources relative to equal increases in energy generation capacity. Coal on the other hand, having the lowest share of energy generation capacity, has a great degree of carbon output than other fossil fuels when undergoing an equal increase in energy generation capacity. This was the case whether imports were oil or coal. Therefore, increasing coal use is not a good prospect for energy management.

In summary, energy generation capacity in Bangladesh increases over the short term 5-year trajectory taken from the PSMP-2016. The percentage share of 
energy generation from gas and oil, in particular, indigenous oil, are the main contributors to energy generation capacity. Both RE and coal increase in energy generation capacity over the 5-year trajectory. Coal, with equal increases in energy generation capacity to other FF is the most polluting FF with regards to carbon output. Gas, on the other hand is the FF that releases the least carbon output relative to equal increases energy generation capacity. RE cannot reduce the huge output of carbon emissions from FF, at least in the short term. We conclude that a mix of energy management practices should be used in collaboration in the long term to optimize the growth in RE. Coal use should be reconsidered as an energy measure, as it contributes to more carbon emission relative to equal energy generation capacity in other FF. The results herein highlight the interconnectivity between FF, RE and carbon emission reduction, provide further understanding of enhancing carbon emission reduction in a mixed energy system. The study also can act as a benchmark for other developing countries, especially those undergoing rapid urbanization.

\section{Conflicts of Interest}

We, the authors, declared no conflicts of interest in this paper.

\section{References}

[1] Lindsey, R. and Dahlman, L. (2020) Climate Change: Global Temperature. Science \& Information for a Climate Smart-Nation, 1-5.

[2] Akadiri, S.S., Alola, A.A. and Akadiri, A.C. (2019) Renewable Energy Consumption in EU-28 Countries: Policy toward Pollution Mitigation and Economic Sustainability. Energy Policy, 132, 803-810. https://doi.org/10.1016/j.enpol.2019.06.040

[3] Li, J. and Li, S. (2020) Energy Investment, Economic Growth and Carbon Emissions in China-Empirical Analysis Based on Spatial Durbin Model. Energy Policy, 140, Article ID: 111425. https://doi.org/10.1016/j.enpol.2020.111425

[4] Saidi, K. and Omri, A. (2020) The Impact of Renewable Energy on Carbon Emissions and Economic Growth in 15 Major Renewable Energy-Consuming Countries. Environmental Research, 186, Article ID: 109567. https://doi.org/10.1016/j.envres.2020.109567

[5] Adams, S. and Acheampong, A.O. (2019) Reducing Carbon Emissions: The Role of Renewable Energy and Democracy. Journal of Cleaner Production, 240, Article ID: 118245. https://doi.org/10.1016/j.jclepro.2019.118245

[6] Omer, A.M. (2019) Energy Use and Environmental Impacts: A General Review. Journal of Renewable and Sustainable Energy, 1, 1063. https://doi.org/10.1063/1.3220701

[7] Huda, A.S.N., Mekhilef, S. and Ahsanab, A. (2014) Biomass Energy in Bangladesh: Current Status and Prospects. Renewable and Sustainable Energy Reviews, 30, 504-517. https://doi.org/10.1016/j.rser.2013.10.028

[8] Madlener, R. and Sunak, Y. (2011) Impacts of Urbanization on Urban Structures and Energy Demand: What Can We Learn for Urban Energy Planning and Urbanization Management? Sustainable Cities and Society, 1, 45-53.

https://doi.org/10.1016/j.scs.2010.08.006

[9] Khan, H., Khan, I. and Binh, T.T. (2020) The Heterogeneity of Renewable Energy 
Consumption, Carbon Emission and Financial Development in the Globe: A Panel Quantile Regression Approach. Energy Reports, 6, 859-867.

https://doi.org/10.1016/j.egyr.2020.04.002

[10] Star, T.D. (2018) Pollution the Killer. The Daily Star, Bangladesh.

[11] Nikolakakis, T., Chattopadhyay, D. and Brazilian, M. (2017) A Review of Renewable Investment and Power System Operational Issues in Bangladesh. Renewable and Sustainable Energy Reviews, 68, 650-658. https://doi.org/10.1016/j.rser.2016.10.016

[12] Ltd E S. (2017) Power Sector Review of Bangladesh. EBL Securities Ltd., Dhaka.

[13] Shiraishi, K., Shirley, R.G. and Kammen, D.M. (2019) Geospatial Multi-Criteria Analysis for Identifying High Priority Clean Energy Investment Opportunities: A Case Study on Land-Use Conflict in Bangladesh. Applied Energy, 235, 1457-1467. https://doi.org/10.1016/j.apenergy.2018.10.123

[14] Islam, S. and Khan, M.Z.R. (2017) A Review of Energy Sector of Bangladesh. Energy Procedia, 110, 611-618. https://doi.org/10.1016/j.egypro.2017.03.193

[15] Hossain, M.F., Hossain, S. and Uddin, M.J. (2017) Renewable Energy: Prospects and Trends in Bangladesh. Renewable and Sustainable Energy Reviews, 70, 44-49. https://doi.org/10.1016/j.rser.2016.11.197

[16] Zhou, S., Wang, Y. and Zhou, Y. (2018) Roles of Wind and Solar Energy in China's Power Sector: Implications of Intermittency Constraints. Applied Energy, 213, 22-30. https://doi.org/10.1016/j.apenergy.2018.01.025

[17] IEA (2020) Global $\mathrm{CO}_{2}$ Emissions in 2019. International Energy Agency, Paris.

[18] Haque, M.A. (2020) Bangladesh Power Sector: An Appraisal from a Multi-Dimensional Perspective (Part-1). EBL Securities Ltd., Dhaka.

[19] Karmaker, A.K., Rahman, M.M. and Hossain, M.A. (2020) Exploration and Corrective Measures of Greenhouse Gas Emission from Fossil Fuel Power Stations for Bangladesh. Journal of Cleaner Production, 244, Article ID: 118645. https://doi.org/10.1016/j.jclepro.2019.118645

[20] JICA (2016) Power \& Energy Sector Master Plan (PSMP2016). BD: People's Republic of Bangladesh Ministry of Power, Energy and Mineral Resources (MOPEMR), Bangladesh Power Development Board (BPDB).

[21] Baky, M.A.H., Rahman, M.M. and Islam, A.K.M.S. (2017) Development of Renewable Energy Sector in Bangladesh: Current Status and Future Potentials. Renewable and Sustainable Energy Reviews, 73, 1184-1197. https://doi.org/10.1016/j.rser.2017.02.047

[22] Wu, F., Huang, N. and Zhang, F. (2020) Analysis of the Carbon Emission Reduction Potential of China's Key Industries under the IPCC $2{ }^{\circ} \mathrm{C}$ and $1.5{ }^{\circ} \mathrm{C}$ Limits. Technological Forecasting and Social Change, 159, Article ID: 120198. https://doi.org/10.1016/j.techfore.2020.120198

[23] Lin, B. and Ahmad, I. (2016) Analysis of Energy Related Carbon Dioxide Emission and Reduction Potential in Pakistan. Journal of Cleaner Production, 143, 278-287. https://doi.org/10.1016/j.jclepro.2016.12.113

[24] Lin, B. and Tan, R. (2017) Sustainable Development of China's Energy Intensive Industries: From the Aspect of Carbon Dioxide Emissions Reduction. Renewable and Sustainable Energy Reviews, 77, 386-394.

https://doi.org/10.1016/j.rser.2017.04.042

[25] Yu, S., Hua, X. and Li, L. (2020) Does the Development of Renewable Energy Promote Carbon Reduction? Evidence from Chinese Provinces. Journal of Environmental Management, 268, Article ID: 110634. 
https://doi.org/10.1016/j.jenvman.2020.110634

[26] Xuan, D., Ma, X. and Shang, Y. (2020) Can China's Policy of Carbon Emission Trading Promote Carbon Emission Reduction? Journal of Cleaner Production, 270, Article ID: 122383. https://doi.org/10.1016/j.jclepro.2020.122383

[27] Ding, L.L., Liang, L. and Zhao, X. (2020) Modelling Energy and Carbon Emission Performance: A Constrained Performance Index Measure. Energy, 197, Article ID: 117274. https://doi.org/10.1016/j.energy.2020.117274

[28] Destek, M.A. and Aslan, A. (2020) Disaggregated Renewable Energy Consumption and Environmental Pollution Nexus in G-7 Countries. Renewable Energy, 151, 1298-1306. https://doi.org/10.1016/j.renene.2019.11.138

[29] Cumberland, J.H. (1966) A Regional Interindustry Model for Analysis of Development Objectives. Regional Science Association International, 17, 65-94. https://doi.org/10.1007/BF01982510

[30] Leontief, W. and Ford, D. (1972) Air Pollution and the Economic Structure: Empirical Results of Input-Output Computations. Input-Output Tech, 9-30.

[31] Bullard, C.W. and Herendeen, R.A. (1975) Energy Impact of Consumption Decisions. Proceedings of the IEEE, 63, 268-278. https://doi.org/10.1109/PROC.1975.9775

[32] Griffin, G.J.L. (1976) Degradation of Polyethylene in Compost Burial. Journal of Polymer Science, 57, 281-286. https://doi.org/10.1002/polc.5070570133

[33] Peng, J., Sun, Y. and Song, J. (2020) Exploring Potential Pathways toward Energy-Related Carbon Emission Reduction in Heavy Industrial Regions of China: An Input-Output Approach. Sustainability, 12, 2148.

https://doi.org/10.3390/su12052148

[34] Jiang, T., Huang, S. and Yang, J. (2019) Structural Carbon Emissions from Industry and Energy Systems in China: An Input-Output Analysis. Journal of Cleaner Production, 240, Article ID: 118116. https://doi.org/10.1016/j.jclepro.2019.118116

[35] Ren, F.R., Tian, Z. and Liu, J. (2020) Analysis of $\mathrm{CO}_{2}$ Emission Reduction Contribution and Efficiency of China's Solar Photovoltaic Industry: Based on Input-Output Perspective. Energy, 199, Article ID: 117493. https://doi.org/10.1016/j.energy.2020.117493

[36] Luo, F., Guo, Y. and Yao, M. (2020) Carbon Emissions and Driving Forces of China's Power Sector: Input-Output Model Based on the Disaggregated Power Sector. Journal of Cleaner Production, 268, Article ID: 121925. https://doi.org/10.1016/j.jclepro.2020.121925

[37] Chard, G., Balatat, M. and Wiedmann, T. (2017) The Use of Environmentally Extended Input and Output Analysis to Measure and Evaluate the Carbon and Employment Footprint of an Equity Investment.

[38] ADP (2017) Guidelines for Estimating Greenhouse Gas Emission of Asian Development Bank Projects: Additional Guidance for Clean Energy Projects. Asian Development Bank, Mandaluyong.

[39] Energia, A. (2020) MAN to Install More than 400 MW Power Gen Capacity in Bangladesh. Gas to Power Journal.

[40] IEA (2019) Bangladesh: 13 Coal-Fired Power Plants to Start Generation by 2023. Clean Coal Centre, London.

[41] Willuhn, M. (2018) JA Solar Supplies Modules to Bangladesh's First Large-Scale Project. PV Magazine, Bangladesh.

[42] Fulwood, M., Henderson, J. and Gomes, I. (2020) Emerging Asia LNG Demand. In- 
stitute for Energy Studies, Oxford. https://doi.org/10.26889/9781784671648

[43] Baul, T.K., Datta, D. and Alam, A. (2018) A Comparative Study on Household Level Energy Consumption and Related Emissions from Renewable (Biomass) and Non-Renewable Energy Sources in Bangladesh. Energy Policy, 114, 598-608. https://doi.org/10.1016/j.enpol.2017.12.037

[44] Ritchie, H. (2019) Which Countries Are Most Densely Populated? Our World in Data.

[45] Chowdhury, N.M. and Hossain, M. (2019) Poverty, Income Inequality and Growth in Bangladesh: Revisited Karl-Marx. American Finance \& Banking Reviews, 4, 1-10. https://doi.org/10.46281/amfbr.v4i2.324 